\title{
Trends and extremes of drought indices throughout the 20th century in the Mediterranean
}

\author{
P. M. Sousa ${ }^{1}$, R. M. Trigo ${ }^{1,2}$, P. Aizpurua ${ }^{3}$, R. Nieto ${ }^{1,4}$, L. Gimeno ${ }^{4}$, and R. Garcia-Herrera ${ }^{3}$ \\ ${ }^{1}$ University of Lisbon, CGUL, IDL, Lisbon, Portugal \\ ${ }^{2}$ Universidade Lusófona, Departamento de Engenharias, Lisboa, Portugal \\ ${ }^{3}$ Universidad Complutense de Madrid - Department of Earth Sciences II, Madrid, Spain \\ ${ }^{4}$ EPhysLab (Environmental Physics Laboratory), Universidad de Vigo, Facultad de Ciencias, Ourense, Spain
}

Received: 20 January 2010 - Revised: 29 September 2010 - Accepted: 12 October 2010 - Published: 5 January 2011

\begin{abstract}
Average monthly precipitation, the original Palmer Drought Severity Index (PDSI) and a recent adaptation to Europe, the Self Calibrated PDSI (scPDSI) have been used here to analyse the spatial and temporal evolution of drought conditions in the Mediterranean during the 20th century. Monthly, seasonal and annual trends were computed for the period 1901-2000 and also for the first and second halves of this period. The statistical significance of trends was obtained with a modified version of the Mann-Kendall test that accounts for serial auto-correlation. The results show a clear trend towards drier conditions during the 20th century in most western and central Mediterranean regions, with the exceptions of northwestern Iberia and most of Turkey that reveal an increase of moisture availability. A Generalized Extreme Values (GEV) analysis was applied to the maximum and minimum regional values of scPDSI, with results pointing towards a significant decline of absolute extreme values in central areas (Italy and Balkans) and a less clear picture emerging in western (Iberia) and eastern (Turkey) realms.

The inter-annual variability of the scPDSI index series is shown to be more realistic than the corresponding PDSI version, fitting better the drought episodes sequence and magnitude described in the literature for each sub-region. We assess the decadal and inter-annual variability of the scPDSI for each sub-domain and evaluate the role played by the major teleconnection patterns, and by several sea surface temperature (SST) anomalies. The main driver of scPDSI in western and central Mediterranean areas is the winter North Atlantic Oscillation (NAO) pattern that is also relevant during the following spring and summer seasons with anti-correlation values below -0.60 . The second most important mode corresponds to the Scandinavian Pattern that is significantly asso-
\end{abstract}

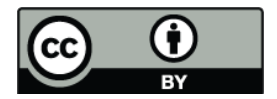

Correspondence to: $\mathrm{R}$. M. Trigo (rmtrigo@fc.ul.pt) ciated to the scPDSI between winter and summer over central Mediterranean (correlation values around 0.50). Finally, the teleconnection and SST analysis has allowed us to calibrate a stepwise regression model, enabling the forecasting of summer drought conditions six months in advance. The final model obtained is capable of reproducing the observed scPDSI time series fairly well, with a correlation coefficient of 0.79 (0.77 after cross-validation) and a significant gain over climatology $\left(\mathrm{SS}_{\mathrm{c}}=59 \%\right)$, while the corresponding result against persistence is more modest $\left(\mathrm{SS}_{\mathrm{p} 6}=11 \%\right)$.

\section{Introduction}

In recent years, a number of studies have been published focusing on the evolution of precipitation, drought conditions and moisture availability in the Mediterranean during the 20th century (e.g., Xoplaki et al., 2004; Trigo et al., 2006; López-Moreno et al., 2009). These works are in reasonable agreement, confirming a decrease in rainfall and moisture availability during the 20th century, except in the easternmost sector (mainly Turkey). As a consequence, severe drought episodes (from both meteorological and hydrological contexts) have become more frequent and persistent late in the century, namely in the Balkans (Xoplaki et al., 2004) and Iberia (Garcia-Herrera et al., 2007). Recently, the work by Altava-Ortiz et al. (2010) highlights the occurrence of very dry decades in the western and central Mediterranean since $1984 / 85$.

The latest IPCC report (2007) supports what most recent studies based on global and regional climate models have been suggesting: that the Mediterranean area will register a general trend towards less precipitation during the 21 st century (e.g., Gibelin and Deque, 2003; Giorgi and Lionello, 2008). The combined effects of precipitation decrease and

Published by Copernicus Publications on behalf of the European Geosciences Union. 
the increment in the surface temperature in the Mediterranean will create important changes in the region's water cycle. The recent work by Mariotti et al. (2008) using CMIP3 multi-model simulations showed that the average model predictions had a $20 \%$ decrease in land surface water availability and a $24 \%$ increase in the loss of fresh water over the Mediterranean Sea due to precipitation reduction and warming-enhanced evaporation. The reduction in the available moisture to precipitate will affect the rainfall averages over land (reduction of the recycling component) and equally over the Mediterranean Sea. In a previous work the same authors showed that the Mediterranean Sea itself was the main source of moisture for the surrounding Mediterranean land areas (Mariotti et al., 2002). In summary, the risk of drought episodes in the Mediterranean basin appears to be rising in recent decades and will maintain that momentum for the immediate future. One should always take into account the complexity of the Mediterranean climate, as that may imply different spatial responses to recent and future climate change, particularly between the eastern and western Mediterranean (Xoplaki et al., 2004; Dünkeloh and Jacobeit, 2003).

Drought indices are an important tool when analysing moisture availability, since they usually do not depend only on rainfall values, but also on temperature or evapotranspiration series, and local water budgets. In the last decade a number of studies have been performed with the aim of developing new indices particularly suited for drought analysis, quantification and monitoring (see the reviews in Heim, 2002 and Keyantash and Dracup, 2002). From a hydrological point of view, Mediterranean droughts are driven both by lack of precipitation and high evaporation rates. Thus, it is important to use an index which takes into account the soil water availability for the vegetation, rather than purely climatic variables (Nicault et al., 2008). That goal can be achieved with the PDSI (Palmer Drought Severity Index), one of the most widely employed drought indices, because it corresponds with a measure of regional moisture availability (Palmer, 1965). The index is based on water supply and demand, which is calculated using a relatively simple water budget system. This budget is based on historic records of precipitation and temperature and the soil characteristics of the area being considered. The computation of the index allows the classification of relative moisture conditions within 11 categories as defined by Palmer (1965). The PDSI was initially developed for the United States but it has been used extensively for areas outside the USA.

Although a good instrument for the purpose of evaluating drought conditions, the original PDSI has some problems when used in other regions, mainly due to different climatic and land cover properties. It has been shown that the application of the PDSI tends to result in an exaggerated frequency of extreme dry or wet spells (e.g., van der Schrier et al., 2006). Therefore, attempts have been made to adapt the PDSI to different climatic regions. In particular, a new formulation called the self-calibrated PDSI (scPDSI) was introduced by Wells et al. (2004). The scPDSI reduces the excessive frequency of extreme events, when compared to the original PDSI. All weighting factors in Palmer's algorithm were empirically derived from a limited amount of data, largely from the US Great Plains, but are frequently treated as fixed parameters regardless of the climate regime in which the index is computed (Wells et al., 2004). In the scPDSI, for each location, the climatic characteristic weighting factors are computed using data from only that location, rather than by using data of a small number of stations from different climates as was done originally (van der Schrier et al., 2006). This scales the departure from normal precipitation with a factor uniquely appropriate to that location and affects the range of values of the self-calibrating PDSI. Similarly, the duration factors are determined using data from that location only, which influences the sensitivity of the index for changes in the moisture regime (Wells et al., 2004; van der Schrier et al., 2006). The scPDSI used here was developed at the Climatic Research Unit (CRU) and employs the original severity scale.

The main objectives of this work are: (1) to perform an analysis on the long-term variability of dry/wet conditions during the 20th century for the entire Mediterranean basin and specific sub-domains, (2) to evaluate the role played by well-known large modes of atmospheric circulation variability and by SST anomalies on the regional inter-annual variability of drought indices, and (3) to evaluate the nature (stationary or not) of extreme values of drought indices for different sub-domains of the Mediterranean.

Data and methods are briefly described in Sect. 2. Detection of significant trends of precipitation and scPDSI is performed in Sect. 3 with an appropriate version of the MannKendall test. We apply a Principal Component Analysis (PCA) in Sect. 4 to detect and analyse major homogeneous areas of drought variability. In Sect. 5, we fit the Generalized Extreme Value (GEV) analysis to evaluate changes in the characteristics of the extreme distributions. The impact of major large-scale atmospheric circulation patterns and of sea surface temperature anomalies in the scPDSI drought index variability is assessed in Sects. 6 and 7. Finally, this information is used to test a simple statistical model for scPDSI hindcasting in Sect. 8. Some conclusions are outlined in the final section.

\section{Data and methods}

\subsection{Data}

The precipitation and scPDSI data were extracted from the CRU (Climatic Research Unit) high-resolution $\left(0.5^{\circ}\right.$ lat $\left.\times 0.5^{\circ} \mathrm{long}\right)$ dataset and for the 1901-2002 period (Mitchell and Jones, 2005). The PDSI used in this work was computed by Dai (2004) and retrieved from the NOAA database. While the PDSI and CRU precipitation series are 
available for the entire globe, the scPDSI data was only available for a window encompassing Europe and a large part (but not all) of the Mediterranean basin, north of $35^{\circ} \mathrm{N}$. Thus, the PDSI dataset has the advantage over the scPDSI of covering the entire Mediterranean basin. However, it suffers from a few caveats. In particular, the coarser grid $\left(2.5^{\circ}\right.$ lat $\left.\times 2.5^{\circ} \mathrm{long}\right)$ is much less detailed than the higher resolution grid available for the scPDSI. Furthermore, after analysing the data series, we have found numerous problems covering the first half of the 20th century, in particular, the PDSI data early in the century is very sparse. Taking these problems into account, we only performed a complete analysis of PDSI for the period 1951-2000. Some missing values in time were substituted by the mean of the values observed in the months immediately before and after. Concerning the few cases of consecutive missing values in time relative to a single gridpoint, we opted to perform a spatial interpolation, i.e., to use the monthly values from the surrounding gridpoints. These changes had to be performed only in 38 gridpoints, i.e., less than $0.1 \%$ of the total number of values used. Nevertheless, the majority of results presented here are related to the scPDSI, which appears to be more appropriate for the Mediterranean. Both indices are only valid over land areas, and they are not bound by upper and lower absolute thresholds. However, values above 2 (below -2 ) are considered wet (dry) episodes, while values above 4 (below -4 ) are considered to correspond to extremely wet (dry) events.

Monthly values of major teleconnection indices were obtained from the Climate Prediction Centre website (CPC, NOAA) for the period 1951-2002. The methodology employed by CPC to identify the Northern Hemisphere teleconnection patterns is based on Rotated Principal Component Analysis RPCA (Barnston and Livezey, 1987) applied to monthly mean standardized $500-\mathrm{mb}$ geopotential height anomalies.

Monthly SSTs for the period 1951-2002 $\left(2.0^{\circ}\right.$ lat $\times 2.0^{\circ}$ long $)$ were acquired from the ERSST.v3 dataset (Extended Reconstruction Sea Surface Temperatures - Smith et al., 2008).

\subsection{Trends significance}

Standard trend tests such as the Mann-Kendall can present misleading results when time series contain many gridpoints with high auto-correlation values (Wilks, 2006). While this may not be an issue for precipitation and temperature, it can be critical for any long-term memory drought index such as PDSI or scPDSI. In this case, it is advisable to use a more robust methodology that takes into account the autocorrelation problem to avoid an overestimation of statistical significance. The mean gridpoint auto-correlation for the detrended scPDSI series is 0.55 , confirming that these high values are not a result of the long-term trends, and the need to use a more strident significance test. That is pre- cisely the objective of the modified Mann-Kendall test proposed by Hamed and Ramachandra (1997) and employed here. The number of degrees of freedom is overestimated in auto-correlated series, so an "effective" number of observations $\left(N_{\mathrm{S}}\right)$ is used rather than the total number of observations $(N)$. Since variance is underestimated in the original test, this modified formulation computes it with a correction factor $\left(N / N_{\mathrm{s}}\right)$ which is multiplied to the original Mann-Kendall variance formulation:

$$
\begin{aligned}
V(S)= & \frac{N(N-1)(2 N+5)}{18} \cdot \frac{N}{N_{\mathrm{s}}} \\
\frac{N}{N_{\mathrm{s}}}= & 1+\frac{2}{N(N-1)(N-2)} \\
& \cdot \sum_{i=1}^{N-1}(N-i)(N-i-1)(N-i-2) \rho_{\mathrm{S}}(i)
\end{aligned}
$$

$N$ is the number of observations, $N_{\mathrm{s}}$ is the "effective" number of observations and $\rho_{\mathrm{S}}(i)$ is the auto-correlation function of the ranks of the observations.

\subsection{Generalized Extreme Values (GEV) analysis}

Following the common approach adopted by the Extremes Research Line within the European project CIRCE (www. circeproject.eu), we applied the Generalized Extreme Values analysis (GEV) to the adopted drought index (scPDSI). It is widely accepted that extremes of many meteorological and hydrological variables can be fitted by one of the three types of GEV distribution, namely: Gumbel (or type I), Fréchet (or type II) and Weibull (or type III) (Coles, 2001). The standard GEV model has three parameters. A location parameter, $\mu$, determines the location or shift of the distribution. In other words, the location parameter determines where the origin will be located. A scale parameter, $\sigma$, determines the scale or statistical dispersion of the probability distribution. If $\sigma$ is large, then the distribution will be more spread out; if $\sigma$ is small then it will be more concentrated. Finally a shape parameter, $\xi$, determines the type of distribution:

- Gumbel distribution function, or type I, $(\xi \rightarrow 0)$;

- Fréchet distribution function, or type II, $(\xi>0)$;

- Weibull distribution function, or type III, $(\xi<0)$.

\section{Trends analysis}

\subsection{Precipitation trends}

Although dryness can be associated with a number of driving factors, lack of precipitation is the most important cause. Thus, we first analyse the long-term behaviour of the precipitation field over the Mediterranean, with the aim of identifying significant trends (positive and negative). This is carried out using the modified Mann-Kendall test. Monthly 

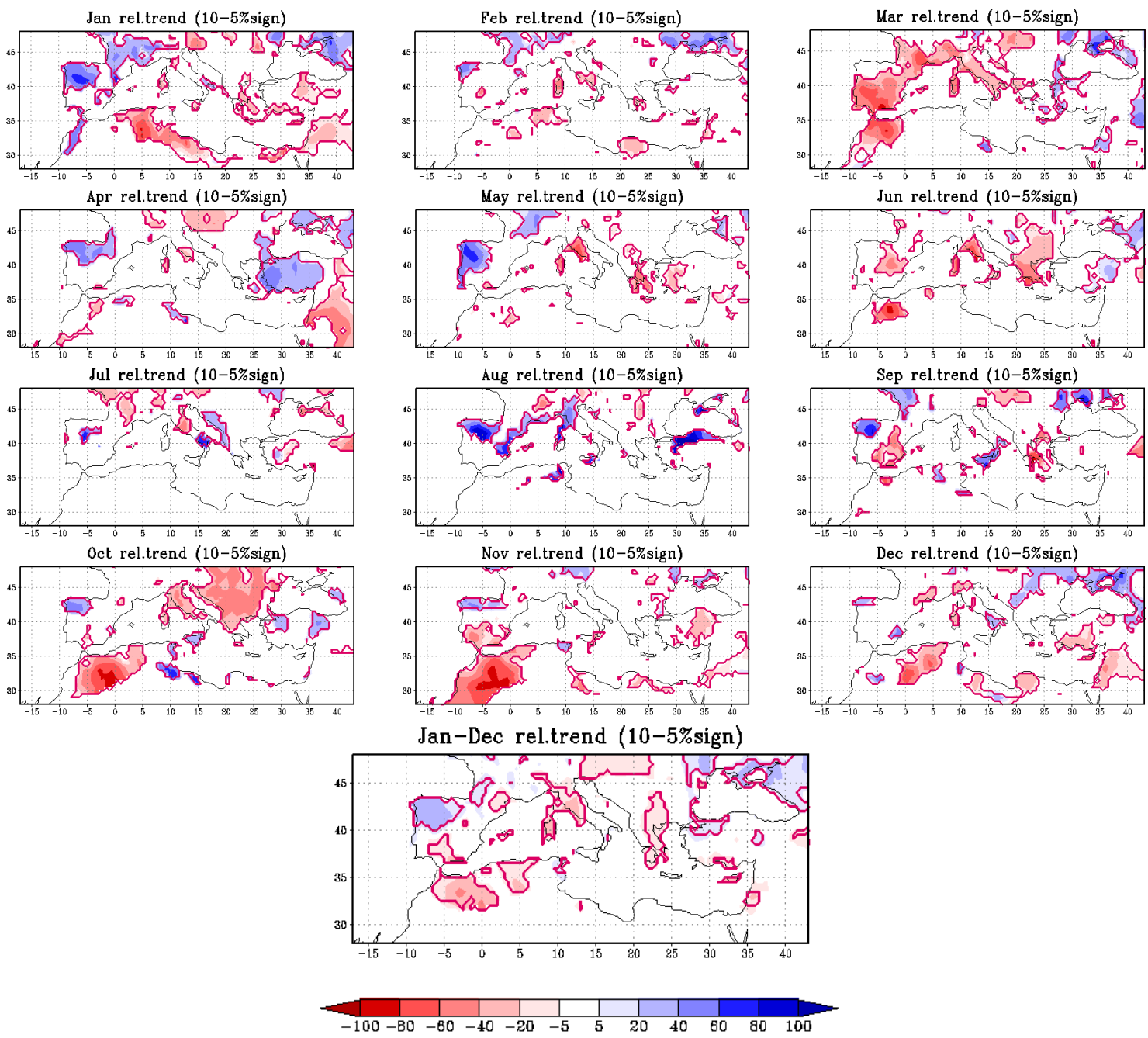

Fig. 1. Relative trends (\%) of mean monthly precipitation (annual, below) in the 1901-2000 period - only areas with mean monthly precipitation above $10 \mathrm{~mm}$ and with statistical significance of $10 \%$ achieved are represented - and circled areas are statistically significant at 5\% (modified Mann-Kendall test).

and seasonal trends were computed relative to the entire 20th century (1901-2000). Trend values were only represented if evaluated to be statistically significant at $5 \%$ or $10 \%$ significance level (Fig. 1). If one considers the entire year, the calculated trends show a progressive and generalized loss of precipitation during the last century in the Mediterranean basin. These negative results are particularly severe in central areas of Italy, but they do exist in most parts of the Mediterranean. Positive trends are only found in Northwest Iberia, some localized areas in the extreme South of Italy, Libya and in Turkey (we must stress the lack of confidence in early century precipitation series for the latter area, due to poor instrumental records). The most dramatic example in this trend for diminishing rains is the month of March, as previously identified by Paredes et al. (2006), although significant loss of precipitation in northern Africa (Morroco and Algeria) between October and De- cember (Fig. 1) is also worth mentioning. This has serious implications in moisture availability, as will be seen in the next section.

\subsection{Mean annual scPDSI trends}

The same procedure used with the precipitation series was applied to the scPDSI series. Trends were computed for the entire 20th century (1901-2000) and the two halves (19011950 and 1951-2000). Regarding the slow variation of the scPDSI in time, mean annual values have been analysed. This index presents a slow response time (at a monthly timescale), with significant inter-annual auto-correlation (typical values close to 0.60 ). Therefore, the straightforward application of the Mann-Kendall test would imply a significant overestimation of the number of degrees of freedom and consequently of the statistical significance. Thus, we applied the test described in Sect. 2.2. 

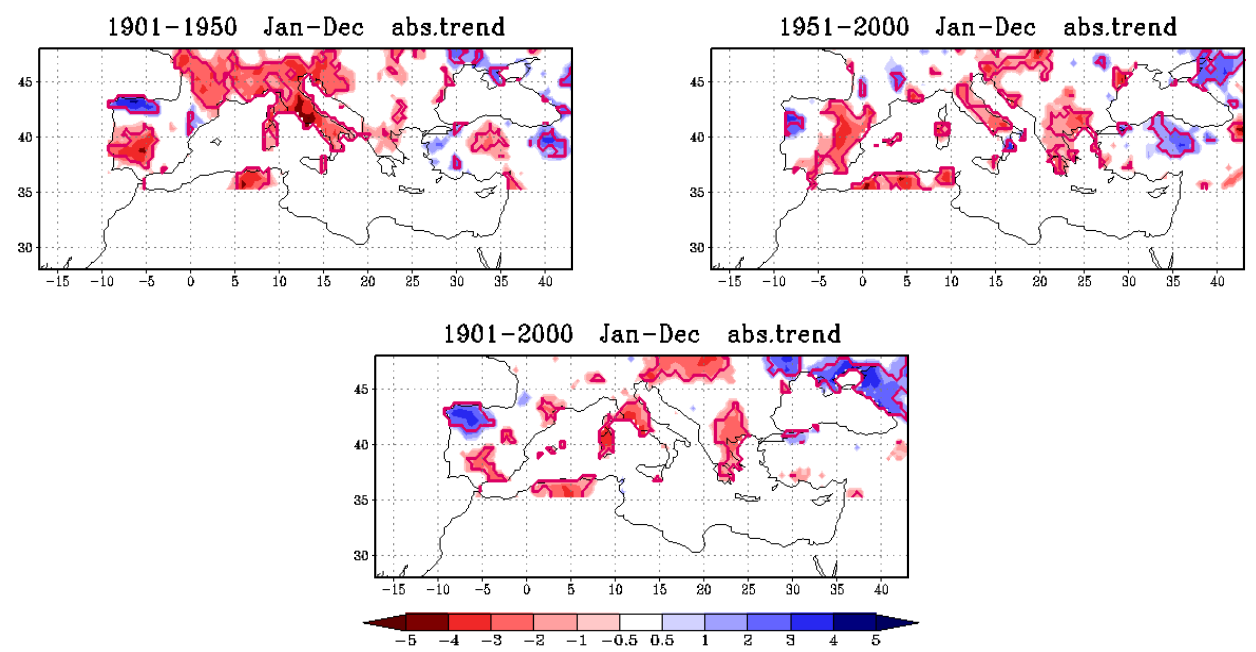

Fig. 2. Mean annual scPDSI absolute trends for the 1901-1950, 1951-2000, and 1901-2000 (down) periods - statistical significance as in Fig. 1.

Looking at the obtained results it is worth stressing that the area encompassing France, Italy and the nearby islands shows important negative trends for the scPDSI (Fig. 2). This development is remarkably severe in central Italy and Sardinia. Very localized positive trends are found during 19512000 in France and in the extreme South of Italy, but they are almost insignificant against the overall loss of moisture availability in the area during the 20th century. This pattern extends southwards to Algeria, but on the other hand, the northern tip of Tunisia tends to present a slight gain in scPDSI values.

Concerning the Iberian Peninsula, we can immediately notice the inverse trends that appear as a dipole with different signals between the NW and the rest of Iberia. A clear positive trend in the scPDSI appears in NW Iberia, meaning an increase in moisture availability in this region during the last century. On the contrary, the generality of the remaining areas of the peninsula and the Balearic Islands present negative trends for the 20th century. These trends are particularly important in the first half of the century in the SW and in the second half in the Mediterranean coast (Fig. 2). The largest part of the coastal strip of the Balkans area does not show significant trends if we consider the entire 1901-2000 period. However, there is a negative trend if one restricts the analysis to 1951-2000. The Greek territory does present a significant decrease in the mean annual scPDSI, with stronger decline for the 1951-2000 period, that is still significant at the centennial scale.

In the eastern sector of the Mediterranean basin, during the first half of the century, Turkey presents a negative trend in the central areas and a positive trend in the western and eastern sectors. These trends revert during the second half of the century. Looking at the entire 20th century, it is characterised by a positive trend in the NW area of Turkey and negative in the southern region. Most of the surrounding areas to the Black Sea present a gain in moisture availability, with the coastal strip of Romania being the main exception. However, we should remind that results for this eastern Mediterranean territory lack confidence prior to the 1930s, due to the smaller availability of good instrumental records.

\section{Regional analysis}

\subsection{Sub-domain definition inside the Mediterranean basin}

In order to reduce the large dimensionality of the fields under analysis, we have performed a standard Principal Component Analysis (PCA) on the PDSI and scPDSI datasets for the Mediterranean basin. There is no single definition of what constitutes the "true" Mediterranean region, here we adopted an area similar to the one proposed by Dünkeloh and Jacobeit (2003), i.e., excluding wetter areas of Europe and desert-like areas as shown in Fig. 4 (top) for scPDSI. The main rationale here is to obtain regions that can be considered relatively homogeneous in terms of drought characteristics. The first four Empirical Orthogonal Functions (EOFs) are shown in Fig. 3 and account for $43 \%$ of the explained variance (EV). This relatively low value of EV by the first four EOFs could be due to the high spatial variability of precipitation and moist availability in the region. The two most relevant patterns correspond to EOF1 and EOF2. EOF1 covers the entire Mediterranean basin (16.4\% of EV), while EOF2 exhibits a W-E pattern (10.1\% EV). The remaining EOF patterns show smaller scale features and explain smaller amounts of variance. Taking into account the EOF patterns of the scPDSI field obtained for the Mediterranean basin, we have considered smaller regions to obtain a more detailed analysis for the 20th century. The selected four sub-regions also take into account the socio-economic relevance of the 


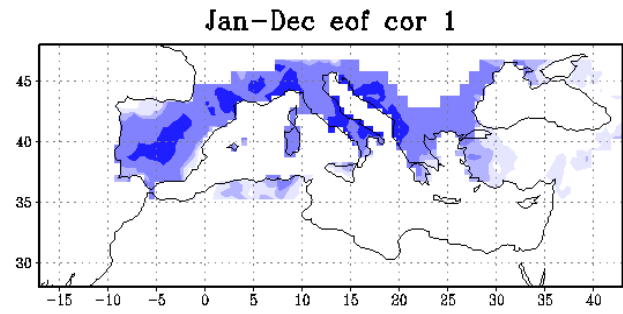

$(16,4 \%)$

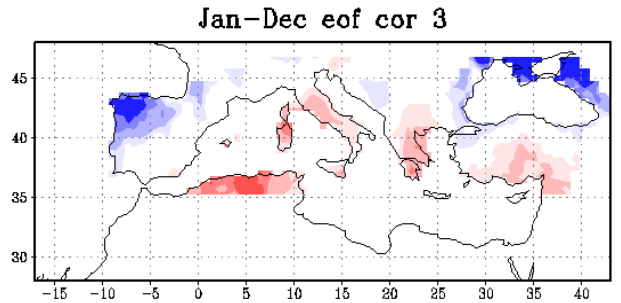

$(8,2 \%)$

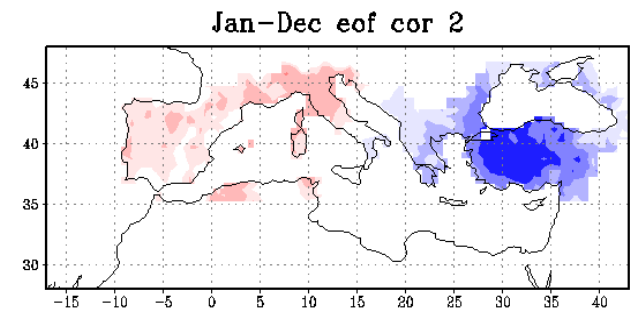

$(10,1 \%)$

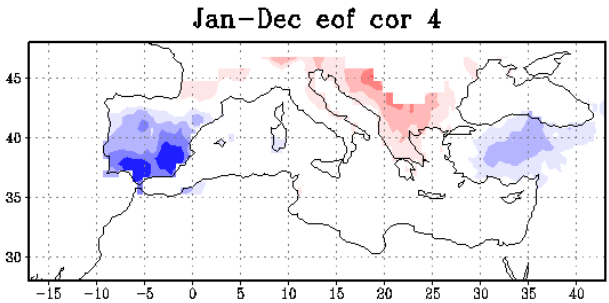

$(6,0 \%)$

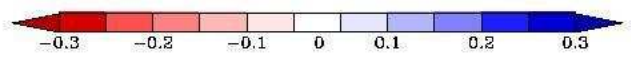

Fig. 3. The first four EOFs (based on the correlation matrix) for the Mediterranean scPDSI index during the 20th century and their contribution to the total variance. Each EOF pattern was multiplied by its corresponding eigenvalue square root, in order to obtain the correlation coefficients between each PC and the original scPDSI field.
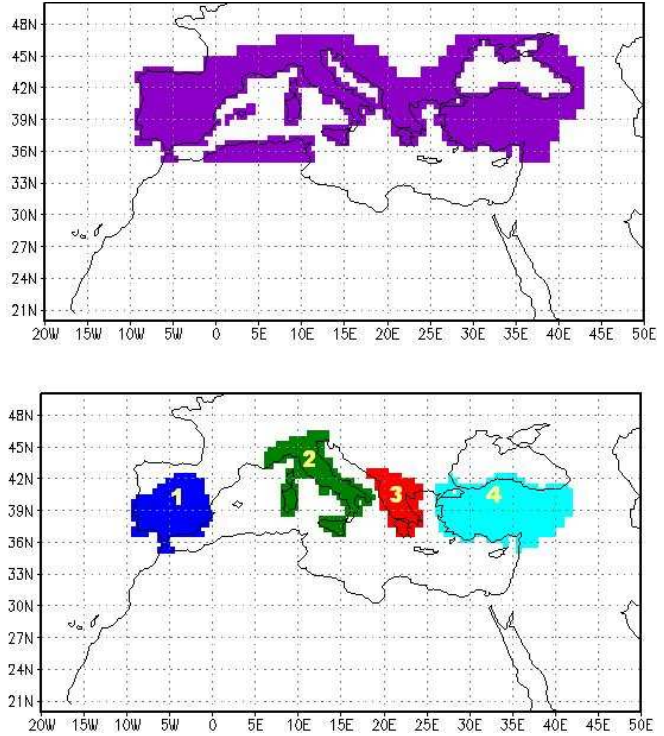

Fig. 4. Representation of the Mediterranean basin and smaller areas considered in this study (for the scPDSI data series).

defined regions and are presented in Fig. 4 (bottom). We have labelled these regions with a simple identification tag to facilitate the following analysis: (1) Iberia; (2) Italian Peninsula; (3) Balkans; (4) Turkey. Unfortunately the scPDSI does not cover the entire Mediterranean basin, only those areas located north of $35^{\circ} \mathrm{N}$ and, thus, excludes Libya and Egypt.

\subsection{Inter-annual variability of regional scPDSI}

Since the scPDSI index varies slowly in time, we show the results obtained for annual averages (although seasonal analysis were also performed). To avoid the excessive smoothing that usually results from estimating spatial averages based on numerous gridpoints, we have multiplied each one of these averages by a spatial scale factor proportional to the area associated to each sub-region. Moreover, based on the severity scale for the scPDSI, we can evaluate the temporal evolution in the percentage of the Mediterranean (and of each sub-region) that is under dry (very dry) or wet (very wet) conditions (as proposed by van der Schrier et al., 2006). Using these methods, a good overview of the last century drought conditions over the entire Mediterranean basin and the smaller regions is now presented.

The first step will be the analysis for the entire Mediterranean basin. Since this region presents so much spatial variability, a grand spatial average will inevitably tend to smooth large inter-annual variations (Fig. 5a). Nevertheless, several periods during the 20th century, namely the 1940s and 1980s, were characterised by fairly generalized dry or wet spells in the Mediterranean basin (Fig. 5a, left). Periods where wet areas exceed dry areas appear to be as frequent as those characterised by predominance of dryness over wet periods. However, some long-lasting episodes with extreme drought conditions cover a wider spatial range (Fig. 5a, right). This means that important and fairly long droughts affecting the 


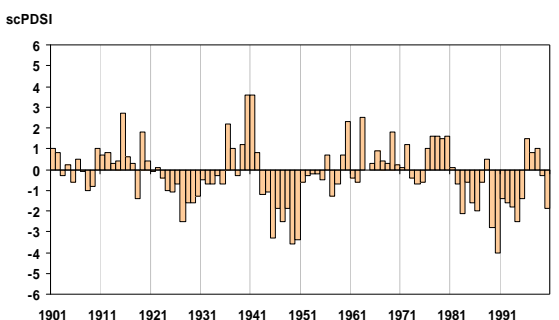

1

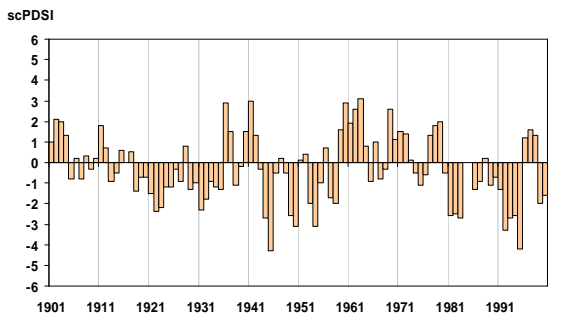

scPDSI

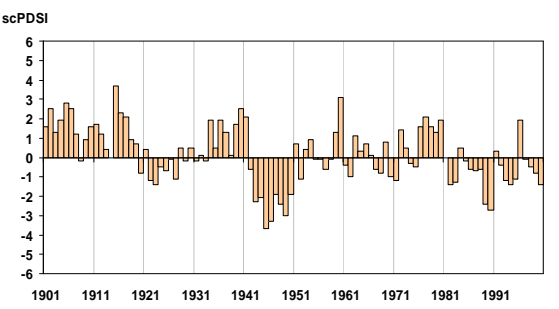

scPDSI

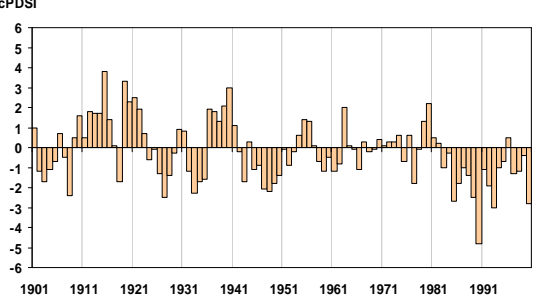

scPDSI

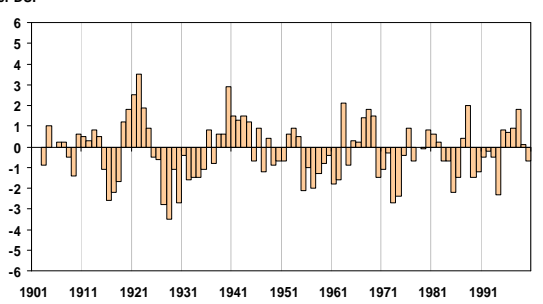

(a)

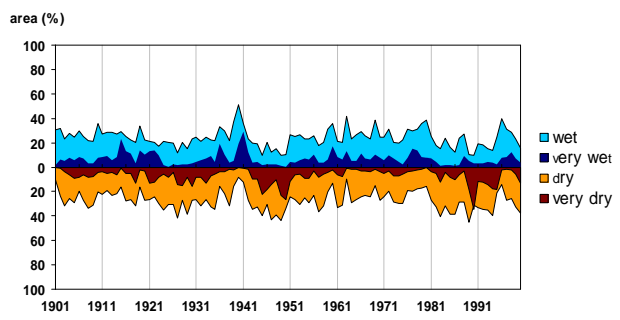

(b)

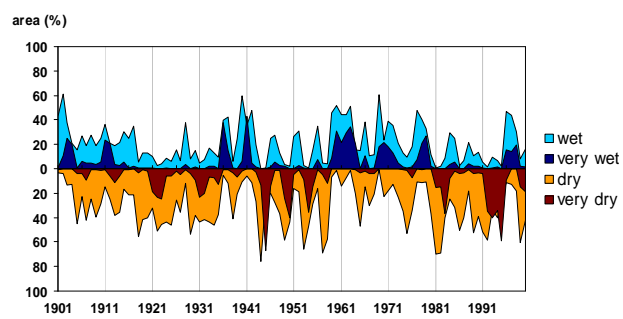

(c)

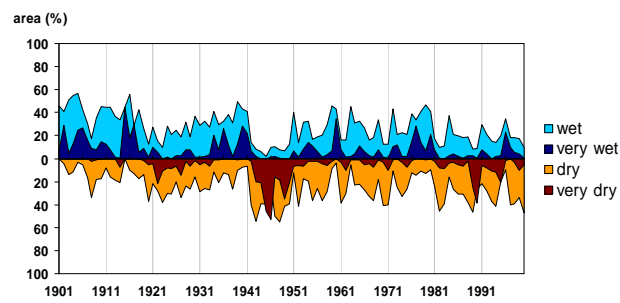

(d)

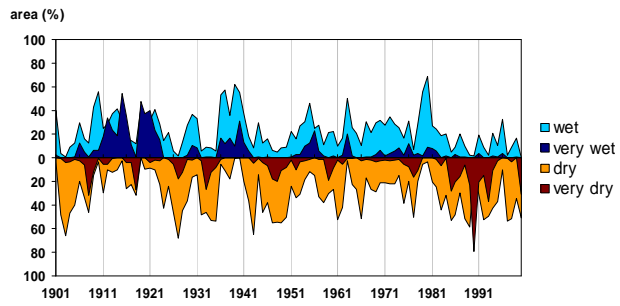

(e)

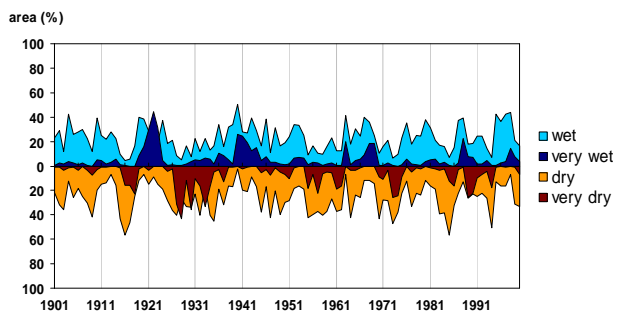

Fig. 5. Inter-annual variability of scPDSI (left) and corresponding percentages of area under wet (blue) and dry (orange) conditions (right) for the considered sub-domains: (a) the entire Mediterranean; (b) Iberia; (c) Italian Peninsula; (d) Balkans; (e) Turkey.

entire Mediterranean basin do occur a few times in a century, but long-lasting periods with generalized excess of water present smaller magnitude. Three of these long droughts occurred in the 20th century. The first one took place later in the 1920s, but cannot be considered too severe. A more severe and generalised drought affected the entire Mediterranean area in the 1940s. Finally, the most severe and prolonged large scale drought in the Mediterranean started in the early 1980s and continued (albeit with smaller amplitude) until the end of the century, having few years of ex- ception. These results are in agreement with those obtained by Xoplaki et al. (2004). Moreover, the negative tendency in the last 25 years is related to a decrease of precipitation in the Mediterranean area (Trigo et al., 2001) and also a negative trend in moisture availability in the Mediterranean region (IPCC, 2007). The wet spells, as stated before, also appear to last for long periods, but with relatively smaller amplitude. The wettest periods dominate the 1910s, late 1930s, and the 1960s and 1970s, in agreement with recent studies of precipitation series (Xoplaki et al., 2004; Trigo et al., 2006). 

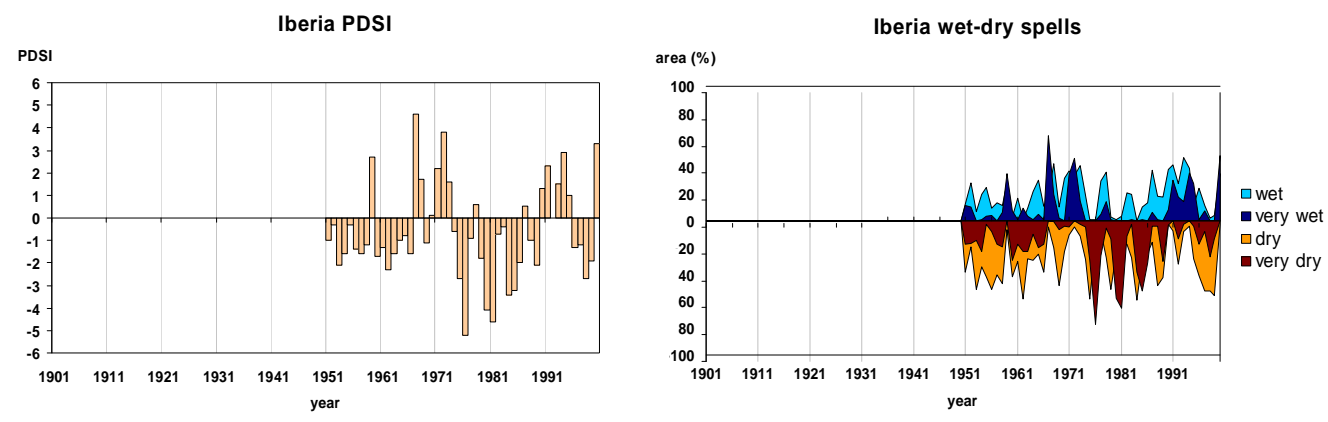

Fig. 6. (left) Inter-annual variability of PDSI for the Iberia region; (right) corresponding percentages of area under wet (blues) and dry (yellows) conditions.

In the Iberian region, like most parts of the Mediterranean (except Turkey), we find two important and generally persistent drought periods: located in the middle of the century, and in the last two decades, with the lowest mean annual scPDSI for Iberia occurring in 1945 (Fig. 5b, left). In fact, in Spain the 1940s are called the "hunger years" due to the famine associated to this drought episode in a country exhausted by the civil war. Interestingly, even for some of the driest years it is possible to find small areas of Iberia with wet characteristics (Fig. 5b, right). Probably this is related to some "generous" frontal activity from the Atlantic reaching the area. Not so severe in intensity, but more persistent in time is the drought that started in the late 1910s, and ended in the mid 1930s. After this drought prone period some very wet years appear. The 1960-1980 period was characterised by several years with high (or even very high) amounts of available soil moisture. Some positive scPDSI years also are present late in the last 10 years of the 20th century, although this period is mostly very dry.

As stated before, the smaller spatial resolution of the PDSI data may imply some loss of information. We use the Iberian region to establish an objective comparison between the two indices. According to the PDSI series, Iberia is characterised by a prolonged and intense dry period in the 1970s and 1980s (Fig. 6). However, these extreme dry conditions over Iberia during the 1970s are not recognised in the literature (GarciaHerrera et al., 2007). In fact if one looks at the scPDSI series, it is possible to find a number of wet years within that period. This comparison confirms the more excessive values presented by the PDSI, when compared to scPDSI (van der Schrier et al., 2006). With these facts in mind, we have restricted the rest of the analysis to the scPDSI drought index.

The Italian region also suffered its most severe drought during mid-century. The 1941-1950 decade only shows positive mean annual scPDSI in 1941. As seen in Fig. 5c (right), during this period the area affected by very dry conditions reached about $50 \%$, with less than $10 \%$ of the territory under wet conditions. The evolution of the dry-wet conditions over Italy resembles what was obtained for Iberia: namely the tendency for drier periods late in the century, a result in accordance with previous works (e.g., Brunetti et al., 2002;
Toreti et al., 2009). Once again, a tendency for slight dryness is found in the 1920s, but unquestionably not as severe as in the western Mediterranean. Again we find a wet spell after this dry one, but the most preeminent wet period appears early in the 20th century. After the severe drought in the 1940s, Italy had some alternating (but generally not severe) conditions, with a slight prevalence of positive scPDSI values (excluding the final two decades).

As we move to the eastern sectors of the Mediterranean, such as the Balkan region (including Greece), we find again some common episodes to those described above. However, it should be stressed that in this area we find more extreme dry and wet episodes (Fig. 5d, left). The scPDSI shows a clear negative tendency, as we see few wet spells later in the century, in clear opposition with the early decades of the century. During the period that spans between 1910s and late 1930s, the Balkans had generally wet or very wet conditions (Fig. 5d, right). Since then, wet spells have become less frequent, and when they occur, they tend to be shorter. On the contrary, the first drought persisting over five years occurred in the 1941-1950 decade (less severe than in Italy), but from 1983 until the end of the century, dry conditions have prevailed. For example, in 1990, nearly $80 \%$ of the territory was very dry, and with the accumulation of years with negative scPDSI, the region as a whole was in extreme drought conditions.

Results obtained for Turkey (Fig. 5e) reveal distinct features from those described for the other areas, although some similarities to the Balkan area can be appreciated. Despite this and unlike Greece, the scPDSI series for Turkey do not show very extreme or persistent episodes (both dry and wet). Wet periods emerge in the early 1920s and early 1940s, while dry conditions are only found in the decade that spans between 1925-1935. However, one must be careful when looking at early 20th century series in this location, as station data is very sparse for that period. The main feature found here is that drought regimes in Turkey are very heterogeneous (Türkeş, 1998; Türkeş et al., 2009), with no evidence of a clear trend for dryness throughout the 20th century (for the Turkish territory as a whole). 
Table 1. Correlation coefficient values between averages of scPDSI time series for the entire Mediterranean basin and the four subdomains. Values in bold are considered statistically significant, taking into account the auto-correlation of the scPDSI index.

\begin{tabular}{lccccc}
\hline & Iberia & Italy & Balkans & Turkey & $\begin{array}{c}\text { Mediterra- } \\
\text { nean }\end{array}$ \\
\hline Iberia & 1.00 & $\mathbf{0 . 4 8}$ & 0.14 & 0.05 & $\mathbf{0 . 6 3}$ \\
Italy & & 1.00 & $\mathbf{0 . 4 4}$ & 0.03 & $\mathbf{0 . 7 3}$ \\
Balkans & & & 1.00 & 0.38 & $\mathbf{0 . 6 6}$ \\
Turkey & & & & 1.00 & 0.22 \\
Mediterra- & & & & & 1.00 \\
nean & & & & & \\
\hline
\end{tabular}

As stated before, the scPDSI series for the Mediterranean basin as a whole are expected to share some similarities to those found in the smaller areas. Larger differences are obtained for Turkey, as this region has in general very distinct time series. It has also some similar periods with the Greece region, as we would expect based on spatial proximity. But comparing it with the most distant area (Iberia), largely distinct patterns are found (Fig. 7). Simply looking at this figure, one could make the assumption that there is a negative correlation in W-E dryness conditions, at least during some sub-periods. In fact, between 1920 and 1960 this is partly true. However, if we analyse the entire century series, it is not the case. Iberia and Turkey do not necessarily have inverted moisture availability patterns associated with a significant negative correlation between the two time series. According to Table 1, these two regions, located in opposite extremes of the Mediterranean, present an extremely low correlation coefficient. The results presented in Table 1 confirm that the moisture availability in Turkey is highly unrelated from what happens in the remaining regions. As a natural result from this correlation table, spatial proximity fosters higher correlation values, since obviously less distant regions have less distinct weather patterns and more similar precipitation series.

\section{GEV analysis results}

The GEV analysis performed here was made possible through the intensive use of the R project language, and of a suit of free software routines, including graphics packages especially developed by several authors for computing extremes in environmental studies (using this specific programming language). A number of different methods have been proposed for parameter estimation in extreme value models (Wilks, 2006). Each technique has its pros and cons, but the all-round utility and adaptability to complex modelbuilding of likelihood-based techniques makes this approach
Iberia VS Turkey scPDSI

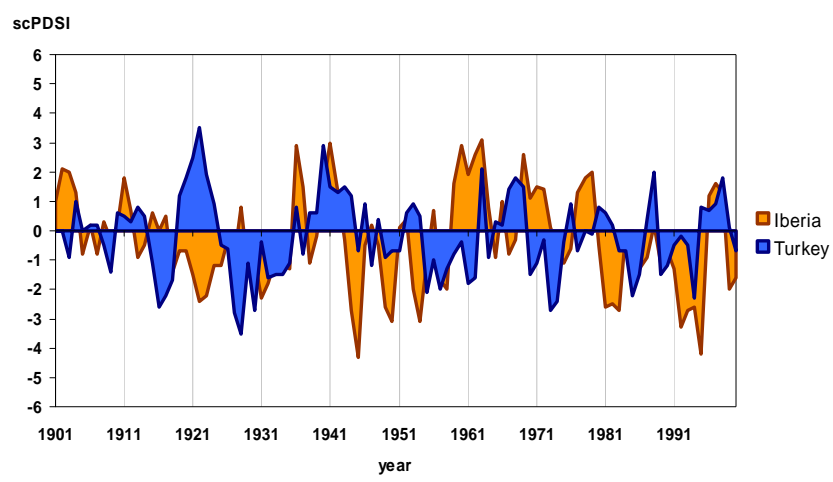

Fig. 7. Comparison between Iberia and Turkey scPDSI series for the 20th century.

particularly attractive. For the purpose of parameter estimating relying on maximum likelihood methods, we used two different packages ("extRemes" and "ismev") available for R project environment and described in Stephenson and Gilleland (2006).

Using the monthly scPDSI values for the 20th century (averaged over the previously considered sub-domains), we computed two new annual series corresponding to the maximum and minimum monthly scPDSI value observed for each year. This procedure was applied to the mean scPDSI series of each sub-domain. Table 2 shows the main results obtained for the different regions considered here. It should be stressed that the best distribution to fit all considered regions corresponds to the Weibull distribution. The value of the parameters is included in columns $2-4$, while column 5 indicates if the distribution is stationary, and the level of statistical significance whenever a trend exists.

It can be seen that Italy and the Balkans show a nonstationary behaviour, with a linear decrease in the location parameter, i.e., a trend towards drier conditions. Higher rank models, or time-dependency for the other parameters ( $\sigma$ and $\xi$ ) were also tested for all the areas, but they did not bring further improvements to be considered as representative of the scPDSI extreme values time series (statistical significance was assessed with a chi-square table - Wilks, 2006). For the sake of brevity, we have focused the analysis on two distinct examples, one characterised by a significant trend (Italy) and another by no trend (Turkey). Figure 8 shows the GEV adjustment for the minimum values in Italy. The upper plots show the time evolution of the annual extremes, while the lower plots show the goodness of fit (a perfect fit should imply all the residuals lying along the diagonals). Figure 9 shows the adjustment obtained for Turkey where, besides the sub-plots relative to the inter-annual evolution and the goodness of fit, we also show the return levels and the probability density plot. 
Table 2. GEV distribution parameters for the maximum and minimum scPDSI time series for the entire Mediterranean basin and the four sub-domains.

\begin{tabular}{lcccc}
\hline Parameter & $\mu$ & $\sigma$ & $\xi$ & Stationary \\
\hline Mediterranean Region & & & \\
\hline Maximum scPDSI & $0.75 \pm 0.22-(0.094 \pm 0.004) \cdot t$ & $1.09 \pm 0.09$ & $-0.30 \pm 0.07$ & No $(p=0.10)$ \\
Minimum scPDSI & $-0.65 \pm 0.22-(0.011 \pm 0.004) \cdot t$ & $1.08 \pm 0.08$ & $-0.30 \pm 0.06$ & No $(p=0.10)$ \\
\hline Iberia & & & \\
\hline Maximum scPDSI & $0.32 \pm 0.20$ & $1.76 \pm 0.15$ & $-0.32 \pm 0.08$ & Yes \\
Minimum scPDSI & $-1.99 \pm 0.17$ & $1.53 \pm 0.11$ & $-0.29 \pm 0.06$ & Yes \\
\hline Italian Peninsula & & & \\
\hline Maximum scPDSI & $1.57 \pm 0.30-(0.014 \pm 0.005) \cdot t$ & $1.46 \pm 0.11$ & $-0.27 \pm 0.07$ & No $(p=0.05)$ \\
Minimum scPDSI & $-0.49 \pm 0.29-(0.018 \pm 0.005) \cdot t$ & $1.42 \pm 0.10$ & $-0.32 \pm 0.05$ & No $(p=0.01)$ \\
\hline Balkans & & & & \\
\hline Maximum scPDSI & $1.70 \pm 0.36-(0.020 \pm 0.006) \cdot t$ & $1.56 \pm 0.30$ & $-0.40 \pm 0.08$ & No $(p=0.02)$ \\
Minimum scPDSI & $-1.28 \pm 0.30-(0.014 \pm 0.005) \cdot t$ & $1.42 \pm 0.11$ & $-0.24 \pm 0.07$ & No $(p=0.05)$ \\
\hline Turkey & & & & \\
\hline Maximum scPDSI & $0.41 \pm 0.15$ & $1.33 \pm 0.10$ & $-0.19 \pm 0.05$ & Yes \\
Minimum scPDSI & $-1.82 \pm 0.13$ & $1.17 \pm 0.09$ & $-0.22 \pm 0.05$ & Yes \\
\hline
\end{tabular}

\section{Italian Peninsula - Minimum scPDSI}

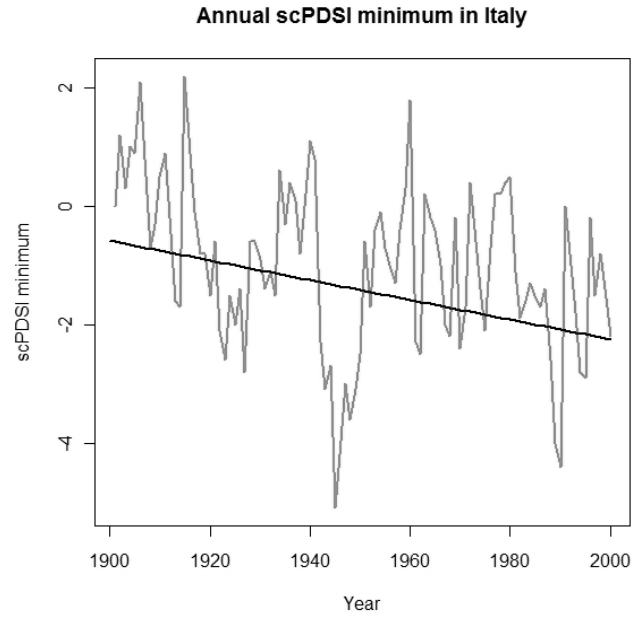

(a)
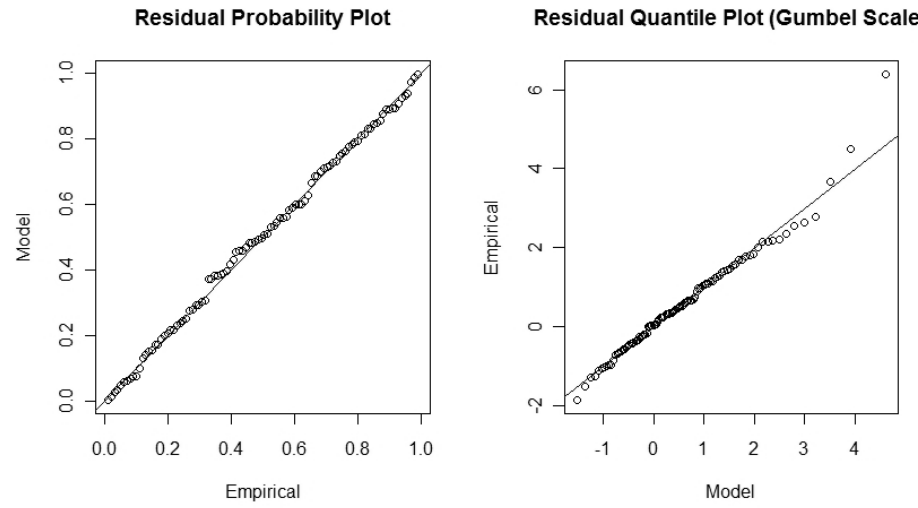

(b)

Fig. 8. (a) Annual scPDSI minimum in the Italian Peninsula; (b) residual diagnostic plots in linear trend GEV model of Italian Peninsula minimum scPDSI data.

\section{Links between scPDSI and large-scale patterns}

The most important large-scale modes of atmospheric circulation in the Northern Hemisphere have been described in the literature (Wallace and Gutzler, 1981; Barnston and Livezey, 1987). Different approaches have been developed over the last two decades to assess the impact of the most relevant modes on the European and Mediterranean climate (e.g., Xoplaki et al., 2004; Dünkeloh and Jacobeit, 2003; VicenteSerrano and López-Moreno, 2006; Trigo et al., 2006). Despite their different methodology, these studies do agree that the most important modes for the Mediterranean climate at the monthly/seasonal time-scale are: (a) the North Atlantic 
Oscillation (NAO), (b) the Eastern Atlantic (EA) pattern, (c) the East Atlantic/Western Russia (EA/WR) pattern, and (d) the Scandinavian pattern (SCAND). A comprehensive assessment of their impact on the Mediterranean precipitation and temperature field can be found in Trigo et al. (2006). Several authors mention the potential relevance of the El Niño-La Niña pattern on the Mediterranean basin, at least for certain areas and seasons (e.g., Trigo et al., 2006; VicenteSerrano, 2005), therefore, we have also included the Southern Oscillation index (SOI) retrieved from the CRU website. Furthermore, the Polar/Eurasia (POL) index was also included in this study, since this teleconnection is related to the strength of the circumpolar circulation (the positive phase reflecting an enhanced circumpolar vortex and the negative phase reflecting a weaker than average polar vortex). These phases may be related to some inter-annual fluctuations in precipitation series. To the best of our knowledge, no previous works have evaluated the impact of these modes on the spatial variability of drought-related fields.

Here we provide a brief overview and potential links between these large-scale patterns and the inter-annual variability of scPDSI series. Monthly data series for the main teleconnections were downloaded from the NOAA website. Seasonal averages with standard months (DJF, MAM, JJA and SON) were computed (1951-2000) for these indices and compared with the mean seasonal scPDSI in two ways: (1) maps of the Pearson correlation coefficient for the entire Mediterranean basin; (2) correlation with regional mean scPDSI time series. These links were evaluated for nonlagged series, and for 3- and 6-month lagged series, i.e., we compared each seasonal scPDSI value with the simultaneous teleconnection index value, but also with those from the previous two climatic seasons. Only the most relevant maps are shown and discussed.

\subsection{Maps of correlation between scPDSI and circulation indices}

The first step evaluating the spatial impact that different atmospheric patterns have in the prevalence of wet or dry conditions in the Mediterranean is a simple correlation map between each circulation mode index and the scPDSI field for the entire area, and for the 1951-2000 period. The widespread anti-correlation pattern between scPDSI values and the NAO index (with the exception of the Black sea area) can be seen in Fig. 10. This pattern reveals an obvious link between dry periods and the positive phase of the NAO during winter, particularly over the western Mediterranean. However, the behaviour of this teleconnection is reflected not only in favouring dry conditions during the winter season (Fig. 10, top), but extends to subsequent climatic seasons, being detectable until the following summer (Fig. 10, bottom), a fact that may be partially explained by the relatively high memory of most drought indices, including the scPDSI.

\section{Turkey - Minimum scPDSI}

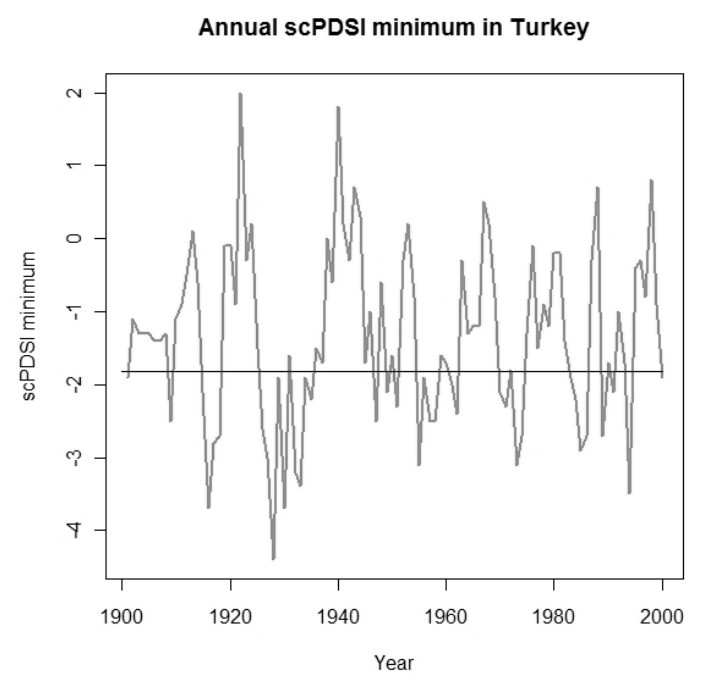

(a)
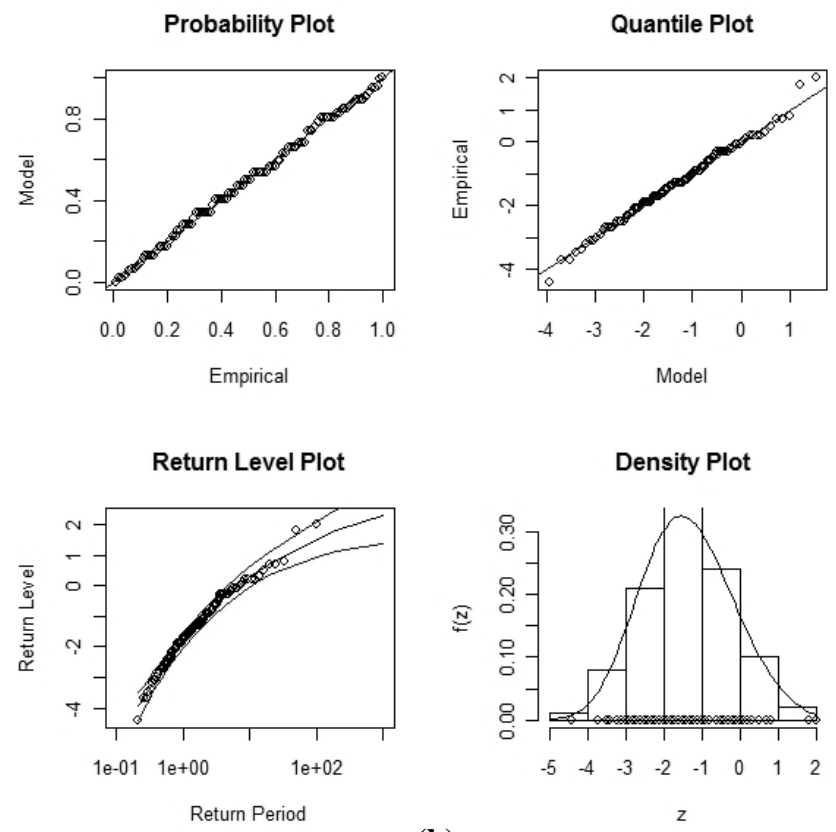

(b)

Fig. 9. (a) Annual scPDSI minimum in Turkey; (b) diagnostic plots for GEV fit to the Turkey minimum scPDSI data.

The SCAND index correlation maps present a less homogeneous pattern with positive values over the central and western Mediterranean but negative over the eastern Mediterranean, namely Turkey (Fig. 11). The influence of the SCAND pattern on the scPDSI is also felt during summer (Fig. 11, bottom) although with less strength than what was achieved with the NAO. The remaining Northern 


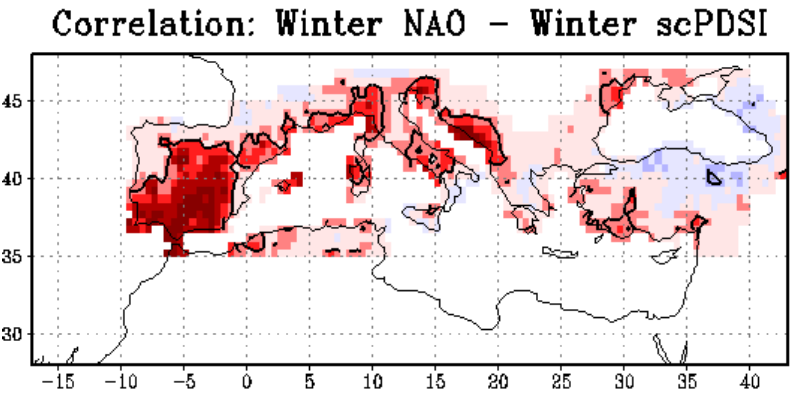

Correlation: Winter NAO - Summer scPDSI

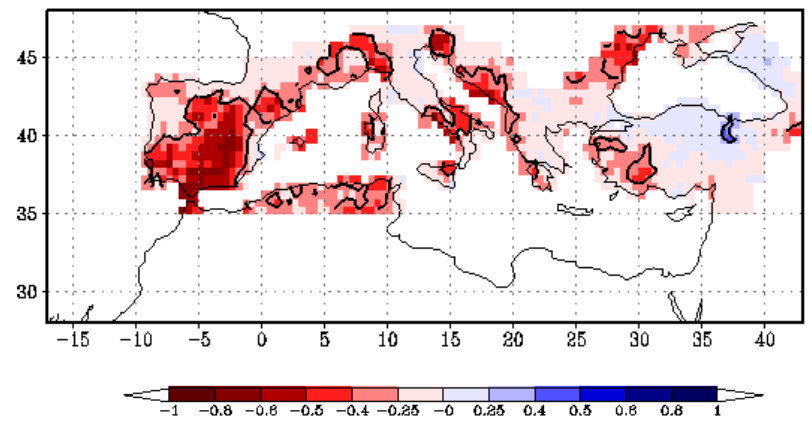

Fig. 10. Correlation between the winter NAO and the winter scPDSI (top) and the following summer scPDSI (bottom) during the 19512000 period - circled areas are statistically significant at $10 \%$.

Hemisphere circulation patterns present less significant or generalized impacts, although some may be important to retain, particularly during winter months such as represented in Fig. 12 for the EA (top) and EA/WR (bottom).

We have also analysed the impact of the major circulation patterns in the inter-annual variability of the seasonal scPDSI index for the entire Mediterranean basin (Table 3). Taking into account the possible effects of trends on overestimating correlation values, we have detrended all time series prior to evaluating the links between the scPDSI and the teleconnection patterns. We have also considered the auto-correlation effect of the scPDSI index (Wilks, 2006). Statistically significant correlation values are highlighted (bold) whenever significant at the 5\% level, and tagged with (*) when significant only at the $10 \%$ level. The winter NAO shows the highest impact on the corresponding winter scPDSI series $(\mathrm{R}=-0.54)$, that extends to spring $(\mathrm{R}=-0.61)$ and summer $(\mathrm{R}=-0.55)$. Similar extended behaviour is found for the winter SCAND index, but with positive correlation values with the average Mediterranean scPDSI series in winter $(\mathrm{R}=0.35)$, in spring $(\mathrm{R}=0.40)$ and summer $(\mathrm{R}=0.48)$. In fact, only the SCAND index presents significant non-lagged links in spring $(\mathrm{R}=0.40)$ and summer $(\mathrm{R}=0.41)$ for this entire domain. The remaining modes of circulation considered do not achieve statistically significant correlation (Table 3 ), although that does not imply that they have an irrelevant role in shaping the evolution of the scPDSI fields.
Correlation: Winter SCAND - Winter scPDSI

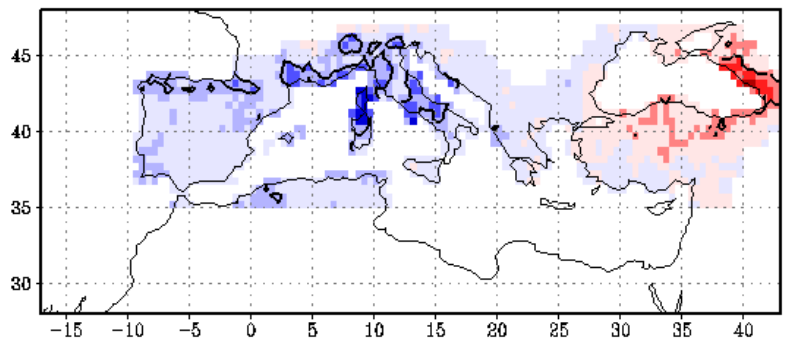

Correlation: Winter SCAND - Summer scPDSI

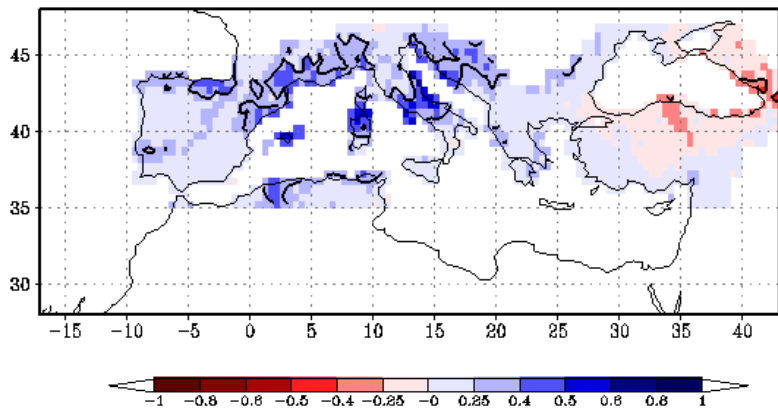

Fig. 11. As in Fig. 10 but for the SCAND pattern.

\section{Correlation: Winter EA - Winter scPDSI}

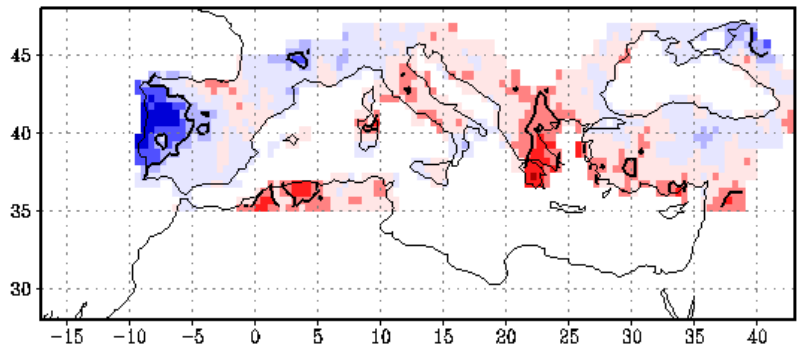

Correlation: Winter EA/WR - Winter scPDSI

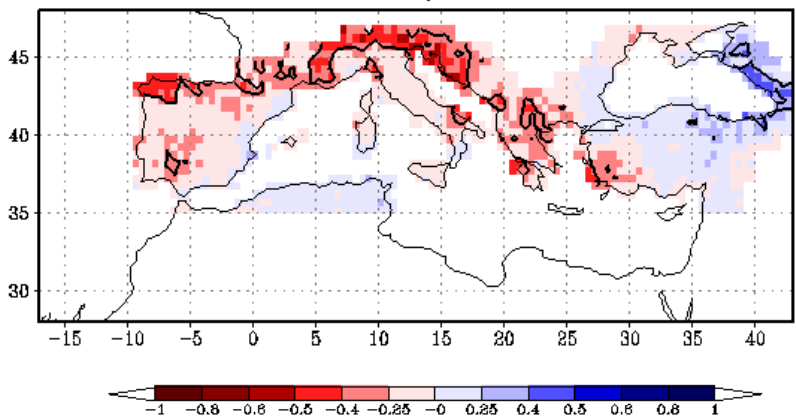

Fig. 12. Correlation between the winter EA and the winter scPDSI (top) and the winter EA/WR and the winter scPDSI (bottom) during the 1951-2000 period - circled areas are statistically significant at $10 \%$.

It is worth noticing that the magnitude of lagged correlation patterns between the winter NAO and spring and summer scPDSI values is higher than the corresponding values obtained between the winter NAO and spring and summer 
precipitation (Trigo et al., 2006). A similar statement can be said about the winter SCAND pattern, which has positive correlation values (around 0.50) with the average Mediterranean scPDSI in winter and also during the following spring and summer, whilst the corresponding lagged correlation values for precipitation quickly degrade to non-significant values. In fact, this relatively stable relationship between the two important circulation modes (NAO and SCAND) in winter and the scPDSI field during the subsequent seasons of spring and summer is not observed with precipitation nor with temperature. Part of this extended impact is related to the intrinsic longer memory of scPDSI time series which also reflects the simultaneous influence of these two circulation modes on winter precipitation, temperature and wind, thus, evapo-transpiration. In this sense we are confident that some of the results obtained here might help to construct seasonal forecast models, or drought warning systems for different Mediterranean sectors as proposed in Sect. 8.

\subsection{Links with the mean scPDSI for the considered sub-domains}

We have repeated the preceding analysis with a focus on the four previously defined Mediterranean sub-domains, but restricting the presentation of results to those pairs of regionsteleconections that show statistically significant correlation values (Table 4). It is immediately noticeable the fact that none of the tested large-scale atmospheric patterns presents significant correlations with the autumn scPDSI. As expected from the wide basin assessment described in the previous section, the winter NAO pattern holds the largest control, although it gradually loses influence towards the east. Nevertheless, when we look at the western (Iberia) and central (Italy and Balkans) regions the winter phase of this teleconnection presents the highest number of (anti-correlated) significant links with the scPDSI variability throughout most of the year. The positive phase of the SCAND pattern (related to the appearance of long-lasting blocking events in northern Europe) overcomes the NAO in Italy (above 0.40) while in the Balkans, the EA and EA/WR present significant anti-correlations (at the $10 \%$ level) with the scPDSI series in winter and summer (above 0.35). In the easternmost sector (Turkey) none of these patterns presents significant links with moisture availability, a fact that is coherent with what we have seen in previous sections where Turkey generally reveals a highly detached behaviour from what we obtained for the other sub-domains, namely concerning scPDSI trends and extremes.

\section{Links between scPDSI and SSTs}

As we have seen in the previous section, an important fraction of the drought conditions variability in the Mediterranean sector can be explained by the major atmospheric patterns of the Euro-Atlantic sector, specially the NAO and
Table 3. Correlation coefficient values between Mediterranean mean scPDSI time series and the considered large-scale atmospheric indices - non-lagged, 3-month and 6-month lagged correlations between the detrended series. Taking into account the autocorrelation of the scPDSI index, values in bold $\left(^{*}\right)$ are considered statistically significant at the 5\% (10\%) level.

\begin{tabular}{|c|c|c|c|}
\hline \multicolumn{4}{|c|}{ Mediterranean } \\
\hline Teleconnection & no lag & 3-month lag & 6-month lag \\
\hline \multicolumn{4}{|c|}{ winter scPDSI } \\
\hline NAO & -0.54 & 0.14 & 0.02 \\
\hline EA & 0.10 & 0.04 & -0.30 \\
\hline EA/WR & -0.29 & 0.31 & 0.22 \\
\hline SCAND & $0.35^{*}$ & 0.19 & 0.25 \\
\hline POL & 0.04 & 0.19 & -0.10 \\
\hline SOI & 0.04 & -0.03 & -0.13 \\
\hline \multicolumn{4}{|c|}{ spring scPDSI } \\
\hline NAO & -0.23 & -0.61 & 0.24 \\
\hline EA & -0.06 & 0.09 & 0.00 \\
\hline EA/WR & 0.06 & 0.06 & 0.26 \\
\hline SCAND & 0.40 & 0.40 & 0.13 \\
\hline POL & -0.11 & -0.11 & 0.27 \\
\hline SOI & 0.15 & 0.10 & -0.18 \\
\hline \multicolumn{4}{|c|}{ summer scPDSI } \\
\hline NAO & 0.03 & -0.14 & -0.55 \\
\hline EA & -0.12 & -0.14 & 0.04 \\
\hline EA/WR & 0.15 & -0.01 & -0.10 \\
\hline SCAND & 0.41 & 0.34 & 0.48 \\
\hline POL & -0.15 & -0.09 & 0.19 \\
\hline SOI & 0.02 & 0.04 & 0.08 \\
\hline \multicolumn{4}{|c|}{ autumn scPDSI } \\
\hline NAO & -0.08 & 0.08 & -0.13 \\
\hline EA & -0.05 & -0.28 & -0.20 \\
\hline EA/WR & 0.01 & 0.13 & 0.09 \\
\hline SCAND & 0.18 & 0.36 & 0.26 \\
\hline POL & -0.17 & -0.11 & -0.09 \\
\hline SOI & -0.06 & -0.12 & -0.03 \\
\hline
\end{tabular}

SCAND. Several studies have shown the links between SSTs and temperature or precipitation series over Europe, including the Mediterranean. Among others, recent works by Hertig et al. $(2010 \mathrm{a}, \mathrm{b})$ have proved successful in using SST information (in the form of SST regimes) as a tool for seasonal forecasting of precipitation and temperature in several subdomains of the Mediterranean. Naturally, as the scPDSI is driven by both precipitation and temperature fields, we have decided to test its level of dependency on SST anomalies. Following the approach devised by Hertig et al. (2010b), we have defined 8 areas over the oceans with potential SST influence on the drought index in the Mediterranean basin, as seen in Fig. 13. 
Table 4. Summary of the large-scale atmospheric indices presenting significant correlation coefficient values (at the 5\% level) with the seasonal scPDSI for each considered sub-region, for non-lagged, 3-month and 6-month lagged series. Values marked with $(*)$ only achieve the $10 \%$ level of statistical significance. All time series were detrended.

\begin{tabular}{lllll}
\hline Sub-region & winter scPDSI & spring scPDSI & summer scPDSI & autumn scPDSI \\
\hline Iberia & winter NAO $(-0.61)$ & previous winter NAO $(-0.63)$ & previous winter NAO $(-0.55)$ & - \\
& winter EA $(0.42)$ & & & \\
\hline Italy & winter SCAND $(0.49)$ & $\begin{array}{l}\text { previous winter SCAND }(0.61) \\
\text { previous winter NAO }(-0.46)\end{array}$ & $\begin{array}{l}\text { previous winter SCAND }(0.49) \\
\text { previous winter NAO }(-0.34)^{*}\end{array}$ & - \\
& winter NAO $(-0.42)$ & summer EA $(-0.35)^{*}$ & - \\
\hline Balkans & winter EA/WR $(-0.36)^{*}$ & - & - & - \\
\hline Turkey & - & - & & \\
\hline
\end{tabular}
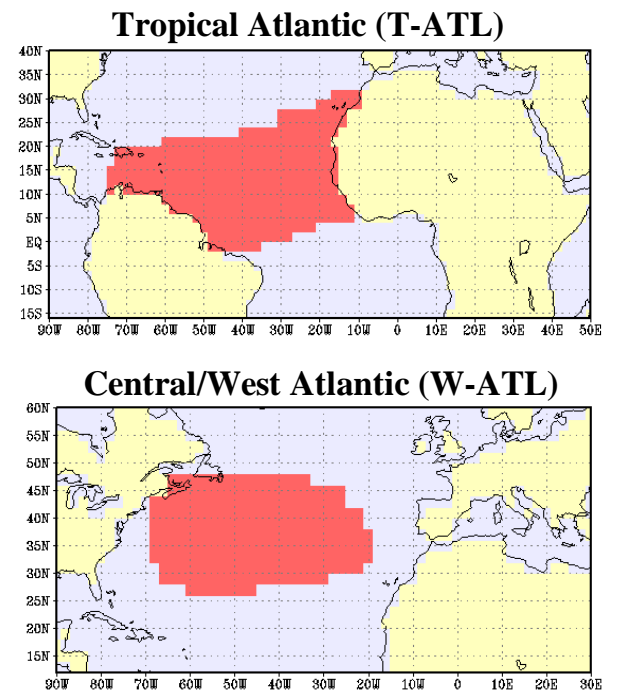

Northeast Pacific (NE-PAC)
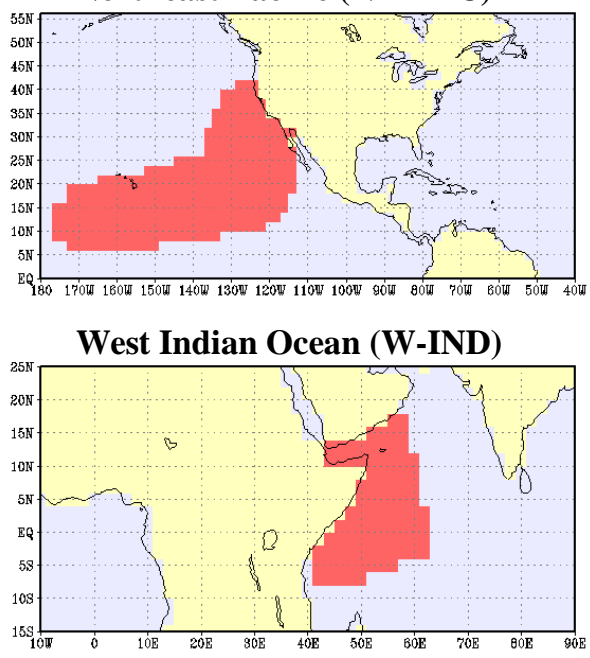

East Atlantic (E-ATL)

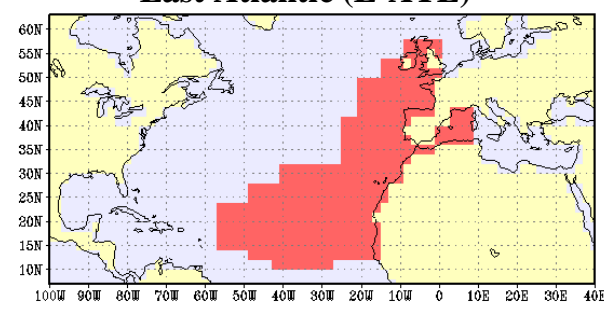

East Pacific (E-PAC)

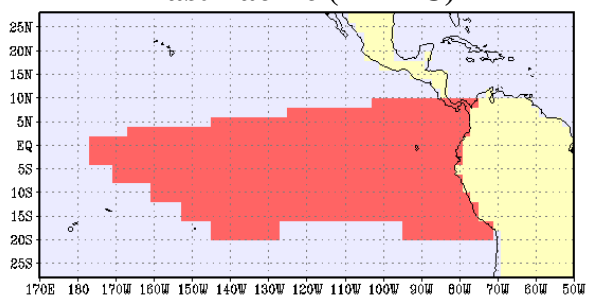

West Pacific (W-PAC)

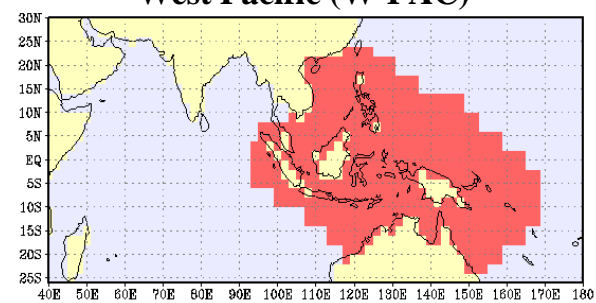

Mediterranean Sea (MED)

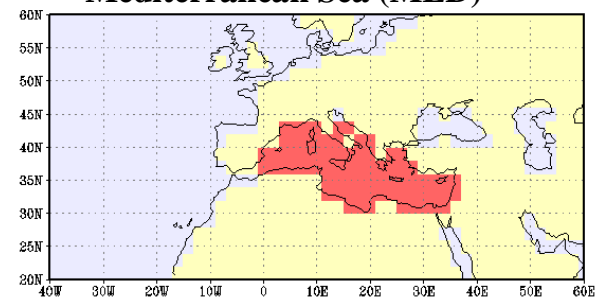

Fig. 13. Spatial representation of the eight oceanic regions considered in this study, with the aim of evaluating the potential influence of SST on the Mediterranean scPDSI fields. Choice of areas was based on Hertig et al. (2010b). 
Table 5. Summary of the SST influence areas presenting significant correlation coefficient values (at the 5\% level) with the seasonal scPDSI for each considered sub-region, for non-lagged, 3-month and 6-month lagged series. Values marked with $\left(^{*}\right)$ only achieve the $10 \%$ level of statistical significance.

\begin{tabular}{|c|c|c|c|c|}
\hline Sub-region & winter scPDSI & spring scPDSI & summer scPDSI & autumn scPDSI \\
\hline Mediterranean & $\begin{array}{l}\text { winter T-ATL }(0.37)^{*} \\
\text { winter MED }(0.33)^{*}\end{array}$ & previous winter T-ATL $(0.37)^{*}$ & $\begin{array}{l}\text { summer E-ATL }(-0.33)^{*} \\
\text { previous spring W-ATL }(-0.36)^{*}\end{array}$ & - \\
\hline Iberia & $\begin{array}{l}\text { winter MED }(0.54) \\
\text { winter T-ATL }(0.40) \\
\text { winter W-IND }(0.39)^{*}\end{array}$ & $\begin{array}{l}\text { spring W-ATL }(-0.36)^{*} \\
\text { previous winter MED }(0.47) \\
\text { previous winter T-ATL }(0.38)^{*}\end{array}$ & $\begin{array}{l}\text { previous spring W-ATL }(-0.36)^{*} \\
\text { previous winter MED }(0.45) \\
\text { previous winter T-ATL }(0.35)^{*}\end{array}$ & - \\
\hline Italy & - & - & $\begin{array}{l}\text { summer MED }(-0.43) \\
\text { previous spring MED }(-0.37)^{*}\end{array}$ & autumn MED (-0.44) \\
\hline Balkans & $\begin{array}{l}\text { winter T-ATL }(0.41) \\
\text { winter E-ATL }(0.32)^{*}\end{array}$ & $\begin{array}{l}\text { spring MED }(-0.36)^{*} \\
\text { previous winter T-ATL }(0.34)^{*}\end{array}$ & & - \\
\hline Turkey & $\begin{array}{l}\text { winter E-ATL }(0.47) \\
\text { winter T-ATL }(0.42)\end{array}$ & $\begin{array}{l}\text { spring T-ATL }(0.43) \\
\text { spring E-ATL }(0.41) \\
\text { previous winter T-ATL } \\
\text { and E-ATL }(0.50)\end{array}$ & $\begin{array}{l}\text { summer E-PAC }(0.34)^{*} \\
\text { previous winter E-ATL }(0.34)^{*} \\
\text { previous winter T-ATL }(0.33)^{*}\end{array}$ & previous summer E-PAC $(0.33)^{*}$ \\
\hline
\end{tabular}

With this in mind, we can now examine correlations between ScPDSI series and the normalized SST series for each of these defined boxes and, similarly to what was done for atmospheric patterns, test links for each sub-region and season, with both lagged and non-lagged comparisons once again. Table 5 provides an overview of the most significant links with SSTs for each considered area. Some significant correlations can be noted (at the $10 \%$ and $5 \%$ levels), but we also need to take a look at correlations slightly below the $10 \%$ level of statistical significance, in order to have a broader understanding of which processes can SSTs drive to influence the scPDSI series in each area.

Some caution is needed when looking at links betweens SSTs and the entire basin as a whole. Nevertheless, the main links point to more moisture availability during the winter months with above normal SSTs in the Atlantic (particularly the T-ATL) and Mediterranean sectors (0.37 and 0.33 , respectively), and on the other hand, to drier conditions in the summer months with above normal SSTs $(-0.33$ in the Eastern Atlantic and -0.28 in the Mediterranean). The winter links are related to higher precipitation amounts associated to those SST patterns and, in fact, these links propagate their signal throughout the following seasons. The summer anticorrelations may not be related to precipitation amounts, but to temperature anomalies connected to those SST anomalies. Above normal temperatures will lead to more evaporation and consequently to below average moisture availability.

Over Iberia, we find the same type of correlation during the wet season, with warm SSTs in the Tropical and Eastern Atlantic (0.40 and 0.29) and in the Mediterranean Sea (0.54) corresponding to moister conditions. Probably connected to the Mediterranean SST, we also find positive correlations with the Western Indian ocean SST (0.39). On the contrary, colder SSTs in the Central/Western Atlantic also favour posi- tive scPDSI values (-0.28). A small link (0.27) with Western Pacific areas is also present for Iberia in winter. These winter links remain during the next seasons, without any significant non-lagged correlations. We should stress once again that the scPDSI has a long memory, with winter conditions influencing the following seasons in terms of drought conditions. Finally, we can point a reasonable anti-correlation between the spring scPDSI in Iberia and the spring SST in Eastern Pacific (-0.26).

Contrasting with Iberia, we do not find important links between SSTs and the scPDSI during winter in Italy, when compared to the links found with atmospheric large-scale patterns. But in the warmer months (from spring to autumn) the Mediterranean SST appears to play an important role in the region's moisture availability. For example, the correlation in summer is -0.43 , and in autumn -0.44. As stated before, this is probably related to heat stress and consequent higher soil water losses in above normal temperature conditions. This effect in the warm months extends even until the following winter, as we find a correlation of -0.28 between the winter scPDSI in Italy, and the previous summer Mediterranean SST anomaly.

This same relation between the warm season SSTs in the Mediterranean and the scPDSI series is found in the Balkans region, but in this case specially in spring $(-0.36)$. Another repeated influence is the prevalence of moist conditions in winters with above average SSTs in the Atlantic sector, namely the T-ATL and E-ATL boxes $(0.41$ and 0.32 , respectively).

As we analyse the Turkey region, we should first bring to mind that no important links with atmospheric patterns were found, so any link with SSTs should be of particular interest in this area. In line with what we have described for other regions, here we find statistically significant 
correlations between the scPDSI and Atlantic SSTs in winter (T-ATL: 0.42; E-ATL: 0.47), and also in Spring (T-ATL: 0.43; E-ATL: 0.41). Interestingly there are significant links between drought conditions in Turkey and SSTs in remote areas, a result that was lacking for the atmospheric teleconnections. There is an important link with the eastern sector of the Pacific, in the El Niño/La Niña area. We found a 0.43 correlation in spring and important lagged correlations (above 0.30) for the summer and autumn months with the same oceanic area.

\section{Modelling the summer scPDSI in the Mediterranean}

We would like to develop a simple model to assess the potential added value provided by the lagged relationships between the scPDSI for the entire Mediterranean and largescale circulation patterns, or SST anomalies. However, the straightforward application of any modelling approach based only on the circulation indices and SSTs as predictors can lead to misleading results due to the high values of autocorrelation of the predictand (scPDSI) field. Thus, any modelling approach must deal with the persistence effect, either by removing it completely (e.g., with ARIMA models) or by incorporating the lagged scPDSI field explicitly (e.g., stepwise regression). Here, we have opted for the latter approach. Thus, a forward stepwise regression was applied to the scPDSI, circulation indices data and normalized SST series in order to forecast mean summer scPDSI for the entire Mediterranean basin. This method tests all possible predictors, looking for the sequence of most appropriate ones after a level of statistical significance is established (we defined the $15 \%$ level). As possible predictors for the model to retain, we relied on mean seasonal (3 month) series of circulation indices and normalized SSTs, relative to winter (autumn) and additionally the seasonal average of scPDSI values for winter (autumn). This corresponds to a 6 (9) month forecast model.

Besides basic ordinary statistics like the mean root square error (RMSE), the mean error (ME) and the Pearson correlation $(R)$, skill scores to compare the models with the climatology and persistence at 6 and 9 months were computed. The skill score is a measure of the percentage of improvement over a benchmark model such as persistence or climatology (Wilks, 2006).

The skill score (SS) for a model with Root Mean Square Error RMSE is given by:

$$
\mathrm{SS}=\frac{\mathrm{RMSE}-\mathrm{RMSEref}}{\mathrm{RMSEperf}-\mathrm{RMSEref}} \cdot 100 \%
$$

where a perfect model would have RMSEperf $=0$. The skill scores relative to the climatology and persistence at 6 and 9 months have been labeled $\mathrm{SS}_{\mathrm{c}}, \mathrm{SS}_{\mathrm{p} 6}$ and $\mathrm{SS}_{\mathrm{p} 9}$, respectively. Using the entire period available, a model was calibrated with six predictors retained, including the mean winter scPDSI as a base (equivalent to the 6-month persistence), the mean winter values of three circulation indices (NAO,
SCAND and POL), one winter SST field (MED) and one autumn SST field (E-ATL), with the following coefficients:

$$
\begin{aligned}
& \mathrm{scPDSI}_{\text {summer }}=0.6346 \mathrm{scPDSI}_{\text {winter }}+0.1979 \\
& \mathrm{E}-\mathrm{ATL}_{\text {winter }}-0.4317 \mathrm{NAO}_{\text {winter }}+0.3919 \\
& \mathrm{SCAND}_{\text {winter }}+0.4396 \mathrm{POL}_{\text {winter }}-0.4012 \mathrm{MED}_{\text {winter }}
\end{aligned}
$$

It is worth noticing that the stepwise regression method did retain some less obvious predictors, namely the POL pattern, rather then some more obvious, like the EA. This choice of predictors reflects the fact that the winter POL appears to retain useful information, despite the correlation value obtained with POL falling slightly below the statistical significance threshold (Sect. 6.2). The inclusion of two SST indices as predictors reinforces the fact that SSTs can be useful at seasonal forecasting time scales. The correlation coefficient between the observed and model time series is very high $(R=0.79)$.

Nevertheless, in order to avoid over fitting, one should calibrate and validate the model in different periods. Here we use the standard cross-validation technique (Wilks, 2006) using 52 years to calibrate and 1 to validate iteratively. Thus, a moving window is applied so that the first run is performed using values for 1951-2001 for constructing and 2002 for validation. On the second run, data for the 1952-2002 is used for construction and 1951 for validation, and so on. While this cannot guarantee that all predictors contribute equally throughout the entire period, it ensures that the results presented are not biased towards any specific period and correspond to an average performance valid for the entire period. The results obtained with this leave-one-out validation method are slightly lower than those with a simple calibration approach presented above, but remain statistically significant at the 5\% level. Thus, the overall correlation coefficient between observed and modelled scPDSI time series is now $R=0.77$. The hindcast of scPDSI values for the 1951-2002 period is shown in Fig. 14, illustrating the relative good capacity of this simple statistical methodology to predict summer scPDSI values based only on autumn and winter information. Moreover, the cross-validated model is better than the use of persistence and climatology as shown by the skill scores attained with objective comparisons with those benchmark models. The gain over climatology is high $\left(\mathrm{SS}_{\mathrm{c}}=59 \%\right)$ while the corresponding result against persistence is more modest $\left(\mathrm{SS}_{\mathrm{p} 6}=11 \%\right)$.

\section{Conclusions and discussion}

Trends of precipitation and scPDSI for the 20th century show a generalized reduction in the precipitation and water availability. Only NW Iberia, the extreme south of Italy, and parts of Turkey show consistent gains in the mean annual precipitation during the last century. However, unlike previous authors, we have applied a modified and more appropriate version of the Mann-Kendall test that accounts for serial 


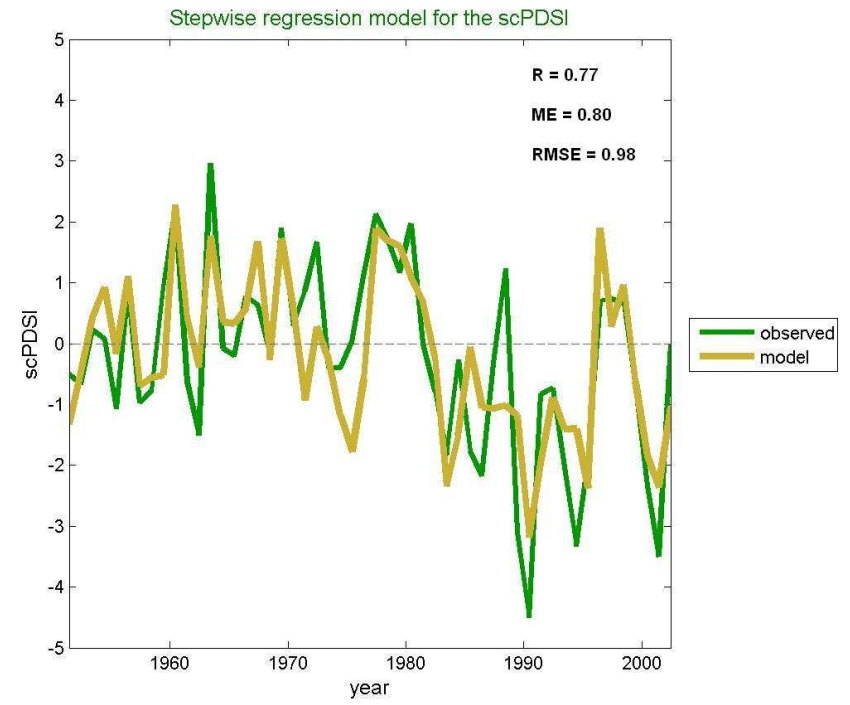

Fig. 14. Hindcast model with cross-validation for the summer scPDSI relative to the entire Mediterranean basin. Also shown are the model's mean error (ME), the root mean square error (RMSE) and the correlation coefficient $(R)$.

correlation resulting in a considerable reduction of the areas characterised by statistically significant trends. This is of paramount importance when evaluating the evolution of the scPDSI, an index that like most drought indices is hampered by relatively high values of auto-correlation.

The application of a GEV analysis led us to find that the Mediterranean basin has been showing smaller values of both annual minimum and maximum scPDSI (non-stationary behaviour). Similar results are obtained when we analyse the sub-domains of Italy or the Balkans, therefore, implying that these areas have been advancing towards drier conditions. Turkey and Iberia are characterised by stationary behaviour when we consider the 100-year time series. This result may simply reflect the fact that both regions include areas with contrasting trends (increase-decrease in moisture).

These results should be considered in light of future climate change scenarios for the Mediterranean. It is well known that some regions are potentially more sensitive to climate change, and according to dynamical modelling (Gibelin and Deque, 2003; Giorgi and Lionello, 2008) and statistical downscaling (Hertig and Jacobeit, 2008) the Mediterranean basin appears to be particularly prone to suffer a significant warming and decrease in precipitation during the 21 st century. In fact, according to Giorgi (2006) the Mediterranean basin corresponds to the most important "hot spot" of climate change in the world. Thus, when evaluating the impact of future climate change scenarios of moisture availability in the region, it is also necessary to assess eventual changes on the location and magnitude of the previously discussed largescale circulation patterns.
We then discussed the role played by major teleconnection patterns, showing that the most influential correspond to the NAO and SCAND patterns during winter. The NAO pattern is known to steer the storm-tracks towards southern (northern) Europe during its negative (positive) phase, thus, increasing (decreasing) the precipitation observed over the Mediterranean. Our results show that the winter NAO impact in the scPDSI field is also significant for the following spring and summer seasons. It is a well-known fact that the NAO index dominates the precipitation variability during the wettest months in the Mediterranean (Brewer et al., 2007). On the other hand, the SCAND mode produces a distinct impact pattern with positive values essentially over central and western Mediterranean areas. Furthermore, the influence of the SCAND pattern also extends to the following summer season, albeit with smaller magnitude than NAO. The remaining Northern Hemisphere circulation patterns (EA and EA/WR), the ENSO and the POL signal show less significant or spatially coherent impacts, although some may be important to consider at the regional scale and/or as input into statistical models. For the easternmost sector (Turkey) none of these patterns presents significant links with moisture availability. It should be stressed that the magnitude of these correlation patterns between the major $\mathrm{NH}$ modes of variability and the Mediterranean scPDSI is similar to the corresponding links obtained with the precipitation field in winter, but is significantly larger in spring and summer (Trigo et al., 2006).

These results raise the prospect of constructing seasonal forecast models, or at least, drought warning systems, particularly tuned for western (Portugal, Spain) and central (Italy, Greece) Mediterranean areas, as these are characterised by an increasing demand of water supply for domestic use, touristic (e.g., golf courses) and agricultural (e.g., intensive fruit plantation) activities. To illustrate this hypothesis, we developed a simple multiple stepwise regression model to hindcast summer scPDSI values between 1951 and 2002. When developing this model, and in addition to the atmospheric indices, we tested SST anomaly series from eight ocean sectors as possible predictors. The correlation analysis between the scPDSI and normalized SST series suggests the possibility of some additional value by incorporating the latter in the model. For example, we found interesting links between water availability and above average SSTs in Atlantic and Mediterranean sectors during winter, or between shortages of available water in summer during above normal SST episodes. All these links described here are well present in the 6-predictor model that was developed. It shows an interesting capacity to predict summer scPDSI values based only on winter and autumn information, and considerably better than climatology or persistence. In this context, it is becoming increasingly relevant to provide seasonal forecasts for hydrological climate variables that can help to alleviate some of the negative impact of climate change on water infrastructure, namely through increased preparedness (Wedgebrow et al., 2002). 
Acknowledgements. This work was supported by the FCT (Portugal) through project ENAC (PTDC/AAC-CLI/103567/2008). This study received support from the EU 6th Framework Program (CIRCE) contract number 036961 (GOCE) and from the Spanish Ministry of Education (MEC) under Grants CGL2008-05968-C0202 and CGL2008-05968-C02-01/CLI. The authors are particularly thankful to the Climatic Research Unit for providing the precipitation and scPDSI fields and also to NOAA for the PDSI. We are in debt to Greg King for his review of the manuscript contents and English standards.

Edited by: P. Lionello

Reviewed by: M. Maugeri and another anonymous referee

\section{References}

Altava-Ortiz, V., Llasat, M., Ferrari, E., Atencia, A., and Sirangelo, B.: Monthly rainfall changes in Central and Western Mediterranean basins, at the end of the 20th and beginning of the $21 \mathrm{st}$ centuries, Int. J. Climatol., in press, doi:10.1002/joc.2204, 2010.

Barnston, A. G. and Livezey, R. E.: Classification, seasonality and persistence of low-frequency atmospheric circulation patterns, Mon. Weather Rev., 115, 1083-1127, 1987.

Brewer, S., Alleaume, S., Guiot, J., and Nicault, A.: Historical droughts in Mediterranean regions during the last 500 years: a data/model approach, Clim. Past, 3, 355-366, doi:10.5194/cp-3355-2007, 2007.

Brunetti, M., Maugeri, M., Nanni, T., and Navarra, A.: Droughts and extreme events in regional daily Italian precipitation series, Int. J. Climatol., 22, 509-621, 2002.

Coles, S.: An Introduction to Statistical Modeling of Extreme Values, Springer, 2001.

Dai, A., Trenbert, K. E., and Qian, T.: A Global Dataset of Palmer Drought Severity Index for 1870-2002: Relationship with Soil Moisture and Effects of Surface Warming, J. Hydrometeorol., 5, 1117-1130, 2004.

Dünkeloh, A. and Jacobeit, J.: Circulation dynamics of Mediterranean precipitation variability 1948-98, Int. J. Climatol., 23, 1843-1866, 2003.

Garcia-Herrera, R., Paredes, D., Trigo, R. M., Trigo, I. F., Hernández, H., Barriopedro, D., and Mendes, M. T.: The outstanding 2004-2005 drought in the Iberian Peninsula: associated atmospheric circulation, J. Hydrometeorol., 8, 483-498, 2007.

Gibelin, A. L. and Deque, M.: Anthropogenic climate change over the Mediterranean region simulated by a global variable resolution model, Clim. Dynam., 20, 327-339, 2003.

Giorgi, F.: Climate change hot-spots, Geophys. Res. Lett., 33, L08707, doi:10.1029/2006GL025734, 2006.

Giorgi, F. and Lionello, P.: Climate change projections for the Mediterranean region, Global Planet. Change, 63, 90-104, 2008.

Hamed, K. H. and Ramachandra, A.: A modified Mann-Kendall trend test for autocorrelated data, J. Hydrol., 204, 182-196, 1997.

Heim, R. R.: A review of twentieth-century drought indices used in the United States, B. Am. Meteorol. Soc., 83, 1149-1165, 2002.

Hertig, E. and Jacobeit, J.: Assessments of Mediterranean precipitations change for the 21 st century using statistical downscaling techniques, Int. J. Climatol., 28, 1025-1045, 2008.
Hertig, E. and Jacobeit, J.: Predictability of Mediterranean climate variables from oceanic variability. Part I: Sea surface temperature regimes, Clim. Dynam., in press, doi:10.1007/s00382-010-0819$\mathrm{x}, 2010 \mathrm{a}$.

Hertig, E. and Jacobeit, J.: Predictability of Mediterranean climate variables from oceanic variability. Part II: Statistical models for monthly precipitation and temperature in the Mediterranean area, Clim Dynam., in press, doi:10.1007/s00382-010-0821-3, 2010b.

Keyantash, J. and Dracup, J.: The quantification of drought: an evaluation of drought indices, B. Am. Meteorol. Soc., 83, 11671180, 2002.

IPCC: Climate Change 2007: The Physical Science Basis, in: Contribution of Working Group I to the Fourth Assessment Report of the Intergovernmental Panel on Climate Change, edited by: Solomon, S., Qin, D., Manning, M., Chen, Z., Marquis, M., Averyt, K. B., Tignor, M., and Miller, H. L., Cambridge University Press, Cambridge, United Kingdom and New York, NY, USA, 2007.

López-Moreno, J., Vicente-Serrano, S., Gimeno, L., and Nieto, R.: Stability of the seasonal distribution of precipitation in the Mediterranean region: Observations since 1950 and projections for the 21st century, Geophys. Res. Lett., 36, L10703, doi:10.1029/2009GL037956, 2009.

Mariotti, A., Struglia, M. V., Zeng, N., and Lau, K. M.: The Hydrological Cycle in the Mediterranean Region and Implications for the Water Budget of the Mediterranean Sea, J. Climate, 15, 674-1690, 2002.

Mariotti, A. Zeng, N., Yoon, J. H., Artale, V., Navarra, A., Alpert, P., and Li, L.: Mediterranean water cycle changes: Transition to drier 21st century conditions in observations and CMIP3 simulations, Environ. Res. Lett., 15, 674-1690, 2008.

Mitchell, T. D. and Jones, P. D.: An improved method of constructing a database of monthly climate observations and associated high-resolution grids, Int. J. Climatol., 25, 693-712, 2005.

Nicault, A., Alleaume, S., Brewer, S., Carrer, M., Nola, P., and Guiot, J.: Mediterranean drought fluctuation during the last 500 years based on tree-ring data, Clim. Dynam., 31, 227-245, 2008.

Palmer, W. C.: Meteorological Drought, Office of Climatology, US Weather Bureau Research Paper No. 45, 1965.

Paredes, D., Trigo, R. M., García-Herrera, R., and Trigo, I. F.: Understanding Precipitation changes in Iberia in early spring: weather typing and storm-tracking approaches, J. Hydrometeorol., 7, 101-113, 2006.

Smith, T. M., Reynolds, R. W., Peterson, T. C., and Lawrimore, J.: Improvements to NOAA's Historical Merged Land-Ocean Surface Temperature Analysis (1880-2006), J. Climate, 21, 22832296, 2008.

Stephenson, A. and Gilleland, E.: Software for the analysis of extreme events: The current state and future directions, Springer, Extremes, 8, 87-109, 2006.

Toreti, A., Fioravanti, G., Perconti, W., and Desiato, F.: Annual and seasonal precipitation over Italy from 1961 to 2006, Int. J. Climatol., 29, 1976-1987, 2009.

Trigo, R. M. and Palutikof, J. P.: Precipitation scenarios over Iberia: a comparison between direct GCM output and different downscaling techniques, J. Climate, 14, 4422-4446, 2001. 
Trigo, R., Xoplaki, E., Zorita, E., Luterbacher, J., Krichak, S. O., Alpert, P., Jacobeit, J., Sáenz, J., Fernández, J., GonzálezRouco, F., Garcia-Herrera, R., Rodo, X., Brunetti, M., Nanni, T., Maugeri, M., Trkes, M., Gimeno, L., Ribera, P., Brunet, M., Trigo, I. F., Crepon, M., and Mariotti, A.: Relations between variability in the Mediterranean region and mid-latitude variability, in: Mediterranean Climate Variability, edited by: Lionello, P., Malanotte-Rizzoli, P., and Boscolo, R., Amsterdam, Elsevier, 179-226, 2006.

Türkeş, M.: Infuence of geopotential heights, cyclone frequency and southern oscillation on rainfall variations in Turkey, Int. J. Climatol., 18, 649-680, 1998.

Türkeş, M., Koc, T., and Saris F.: Spatiotemporal variability of precipitation total series over Turkey, Int. J. Climatol., 29, 10561074, 2009.

van der Schrier, G., Briffa, K. R., Jones, P. D., and Osborn, T. J.: Summer moisture variability across Europe, J. Climate, 19, 2818-2834, 2006.

Vicente-Serrano, S. M.: El Niño and La Niña influence on drought conditions at different time scales in the Iberian Peninsula, Water Resour. Res., 41, W12415, doi:10.1029/2004WR003908, 2005.
Vicente-Serrano, S. M. and López-Moreno, J.: The influence of atmospheric circulation at different spatial scales on winter drought variability through a semi-arid climatic gradient in Northeast Spain, Int. J. Climatol., 26, 1427-1453, 2006.

Wallace, J. M. and Gutzler, D. S.: Teleconnections in the geopotential height field during the Northern Hemisphere winter, Mon. Weather Rev., 109, 784-812, 1981.

Wedgebrow, C. S., Wilby, R. L., Fox, H. R., and O'Hare, G.: Prospects for seasonal forecasting of summer drought and low river flow anomalies in England and Wales, Int. J. Climatol., 22, 219-236, 2002.

Wells, N., Goddard, S., and Hayes, M. J.: A self-calibrating Palmer Drought Severity Index, J. Climate, 17, 2335-2351, 2004.

Wilks, D. S.: Statistical Methods in the Atmospheric Sciences, International Geophysics Series, Academic Press, 2006.

Xoplaki, E., González-Rouco, J. F., Luterbacher, J., and Wanner, H.: Wet season Mediterranean precipitation variability: influence of large-scale dynamics and trends, Clim. Dynam., 23, 63-78, 2004. 